\title{
LULUCF | Land Use, Land-Use change and forestry
}

Reading Guide

Methods \&

Reporting

\begin{tabular}{l|l}
\hline Introduction & Accounting Rules \\
\hline
\end{tabular}

Emission Register

Greenhouse Gas Emissions

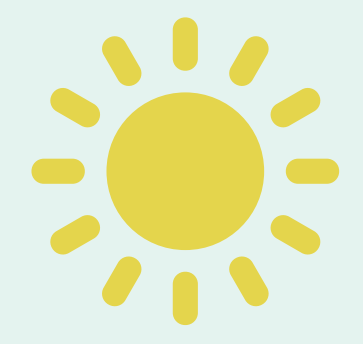

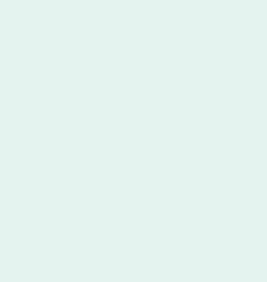

Forest Land

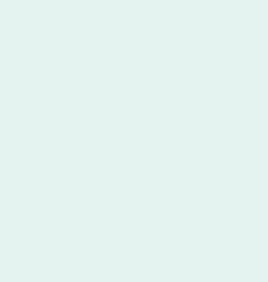

Cropland

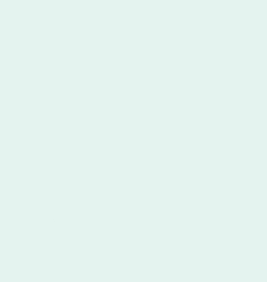

Grassland

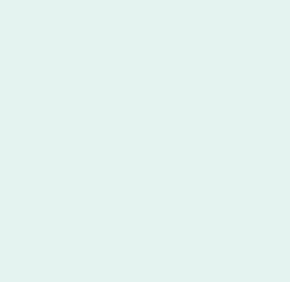

Wetlands

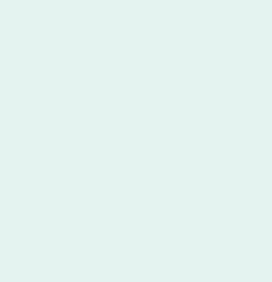

Settlements

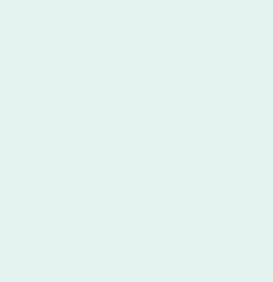

Other Land

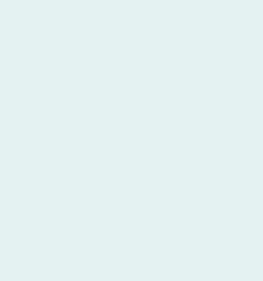

Harvested Wood Products

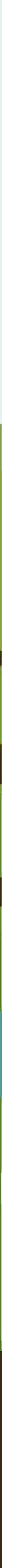




\section{Reading Guide}

This interactive pdf describes the monitoring and reporting of emissions and removals of greenhouse gases from land use, land-use change and forestry (LULUCF) in the Netherlands. The Introduction gives more information about the LULUCF sector in the Netherlands.

\section{Navigating this interactive pdf}

The greenhouse gas reporting for the LULUCF sector is divided into six land use categories: Forest Land, Cropland, Grassland, Wetlands, Settlements and Other Land. In the chapters on these land use categories you will find more information on the definitions and methods used as well as data on the areas and emissions for each land use category. In addition to the land use categories, the Harvested Wood Products category is also a significant carbon pool not directly connected to land use.

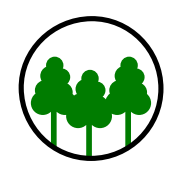

Forest Land

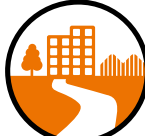

Settlements

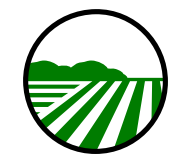

Cropland

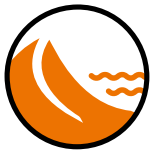

Other

Land

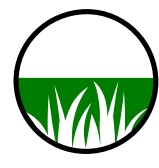

Grassland

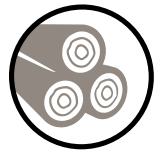

Wood Product

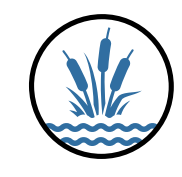

Wetlands
The monitoring and reporting of emissions and removals from the LULUCF sector for inclusion in the Netherlands Pollutant Release and Transfer Register is carried out by the LULUCF task force. More information on this is given in the Emission Register chapter. The Methods and Reporting chapter contains information on the LULUCF methodologies used for each of the reports. The Accounting Rules chapter explains the rules for LULUCF greenhouse gas accounting. Information about reported greenhouse gas emissions and removals from the LULUCF sector is given in the Greenhouse Gas Emissions chapter

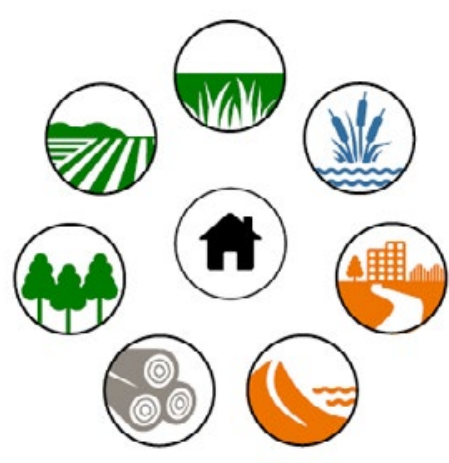

\section{Icons}

You can use the icons in the bottom right-hand corner of each page to navigate to the various land use categories and the start page.

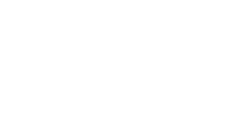

\section{Navigation arrows}

If a topic covers more

than one page you will see navigation arrows in the white space at the bottom right, which you can use to navigate within the topic.

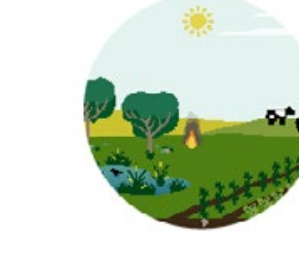

Reading Guide

Introduction

Emission Register

Methods \& Reporting

Accounting Rules

Greenhouse Gas Emissions

Sources | colofon

Navigation bar

You can use the navigation

bar on the right-hand

side of the page to jump

to topics by clicking on a

topic or icon.

\section{Reading Guide}

\section{Introduction}

\section{Emission Register}

Methods \& Reporting

\section{Accounting Rules}

$\overline{\text { Greenhouse Gas Emissions }}$

\section{Sources | colofon}

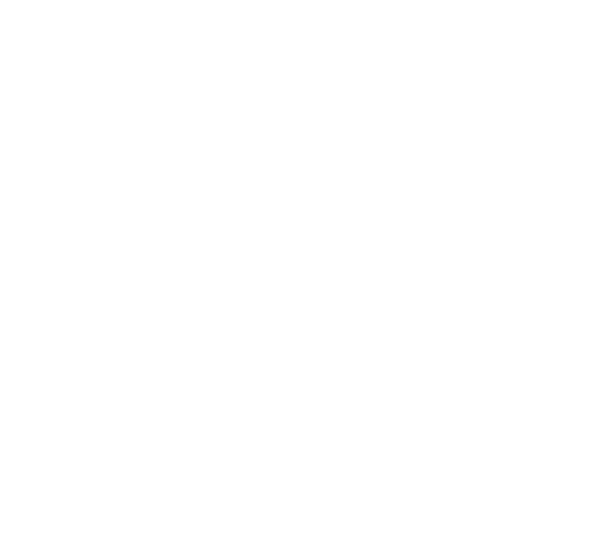




\section{List of abbreviations}

\begin{tabular}{|c|c|c|c|}
\hline ARL & Afforested land & MFL & Managed forest land \\
\hline CBS & Statistics Netherlands & MGL & Managed grassland \\
\hline $\mathrm{CH}_{4}$ & methane & MMR & EU Greenhouse Gas Monitoring \\
\hline $\mathrm{CO}_{2}$ & Carbon dioxide & & Mechanism Regulation \\
\hline $\mathrm{CO}_{2}$ eq & $\mathrm{CO}_{2}$ equivalent, see also box & MWL & Managed wetlands \\
\hline \multirow[t]{3}{*}{ CRF } & Common Reporting Format, general & NFI & Dutch forest inventory \\
\hline & tables for reporting greenhouse gas & NECD & National Emissions Ceilings Directive (EU) \\
\hline & inventories under the UNFCCC & NECP & National Energy and Climate Plan \\
\hline DL & Deforested land & NFAP & National Forestry Accounting Plan \\
\hline ESR & Effort Sharing Regulation (EU) & NIE & National Inventory Entity \\
\hline EU & European Union & NIR & National Inventory Report \\
\hline \multirow[t]{3}{*}{ EZK } & Ministerie van Economische Zaken en & $\mathrm{N}_{2} \mathrm{O}$ & nitrous oxide \\
\hline & Klimaat (Ministry of Economic Affairs & $\mathrm{O}_{2}$ & oxygen \\
\hline & and Climate Policy) & PA & Paris Agreement (Paris climate accords, 2015) \\
\hline FRL & Forest reference level & PBL & Netherlands Environmental Assessment Agency \\
\hline \multirow[t]{2}{*}{ IenW } & Ministerie van Infrastructuur en Water & PRTR & Pollutant Release and Transfer Register \\
\hline & (Ministry of Infrastructure and Water Management) & RIVM & National Institute for Public Health and \\
\hline IPCC & Intergovernmental Panel on Climate Change & & the Environment \\
\hline KP & Kyoto Protocol & UN & United Nations \\
\hline \multirow[t]{2}{*}{ LNV } & $\begin{array}{l}\text { Ministerie van Landbouw, Natuur en } \\
\text { Voedselkwaliteit (Ministry of Agriculture, }\end{array}$ & UNFCCC & $\begin{array}{l}\text { United Nations Framework Convention } \\
\text { on Climate Change }\end{array}$ \\
\hline & Nature and Food Quality) & WEM & Werkgroep Emissie Monitoring \\
\hline \multirow[t]{2}{*}{ LSK } & Landelijke Steekproef Kaarteenheden, a & & (Working Group on Emission Monitoring) \\
\hline & national sample survey of soil map units & WOT N\&M & Wettelijke Onderzoekstaken Natuur \& Milieu \\
\hline LULUCF & Land use, land-use change and forestry & & (Statutory Research Tasks Nature \& Environment) \\
\hline $\mathrm{MCL}$ & Managed cropland & WUR & Wageningen University \& Research \\
\hline
\end{tabular}

\section{Reading Guide}

\section{Introduction}

Emission Register

Methods \& Reporting

Accounting Rules

Greenhouse Gas Emissions

Sources | colofon

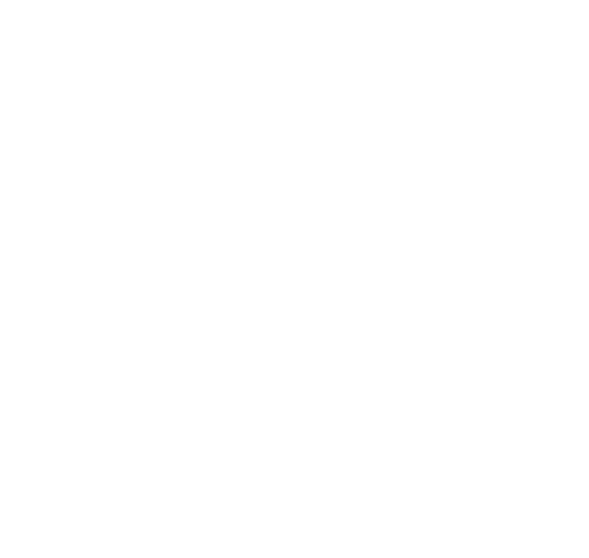




\section{Introduction}

Global warming has major consequences for people, nature and the environment. The cause of these changes in the climate is the global emissions of greenhouse gases. To limit the heating of the earth resulting from greenhouse gas emissions, the Netherlands has committed itself, among other things, to meeting the targets set under the United Nations Framework Convention on Climate Change (UNFCCC). The parties to the Convention have agreed to report annually on national emissions and removals of greenhouse gases. Identifying and quantifying these emissions enables governments to develop policies to reduce emissions, and so it is important that each country determines these emissions in a uniform manner. In this publication the Netherlands LULUCF task force describes the methodology for determining the emissions and removals of greenhouse gases from land use, land-use change and forestry, the LULUCF sector

\section{The impact of LULUCF on the climate}

Land use, land-use change and forestry play a major part in the global climate problem, and how forests are managed has a big impact on the climate. Growing forests and vegetation remove $\mathrm{CO}_{2}$ from the atmosphere and store carbon in biomass (wood) and soil. The way land is used determines the degree to which forests, vegetation and soils can sequester carbon, and whether and for how long the carbon can be stored in this form. Planting new forests (afforestation) and good soil management increases the sequestration of atmospheric $\mathrm{CO}_{2}$ in the carbon pools of the LULUCF sector, while other land-use changes, such as deforestation, intensive land use and drainage of peat soils increases emissions of $\mathrm{CO}_{2}$ from carbon stored in the soil and biomass.
The parties to the Paris Agreement have agreed to take measures to prevent dangerous climate change by keeping the average global temperature rise to no more than 1.5 to $2^{\circ} \mathrm{C}$. To achieve that, in the second half of this century net greenhouse gas emissions must not rise and the remaining emissions must be compensated by the removal of greenhouse gases. It is unlikely that it will be possible to avoid all non- $\mathrm{CO}_{2}$ emissions (such as emissions of methane and nitrous oxide from agriculture/livestock) and so it will therefore be necessary to invest more in greenhouse gas capture. In addition to the as yet uncertain technological innovations that will be needed, forests, vegetation and soils will have to play an important part.

It is therefore essential to determine the emissions from the LULUCF sector and hold countries to account for their performance in tackling climate change by rewarding reductions in emissions and increased carbon sequestration and discouraging higher emissions and reduced sequestration.

\section{Other sectors}

Besides LULUCF, emissions and removals from five other sectors are also reported to the UN Climate Convention: energy, industrial processes and product use, agriculture, waste and transport. Agriculture and land use are two separate but related sectors. In general, land use in LULUCF covers all $\mathrm{CO}_{2}$ and non- $\mathrm{CO}_{2}$ emissions from soils that are related to the use of agricultural land. The other non- $\mathrm{CO}_{2}$ emissions, for example from livestock and use of manure fall under the agricultural sector. LULUCF is therefore concerned only with the consequences of land use and not agricultural activities themselves (see Figure 1).
Reading Guide

\section{Introduction}

\section{Emission Register}

Methods \& Reporting

\section{Accounting Rules}

Greenhouse Gas Emissions

\section{Sources | colofon}

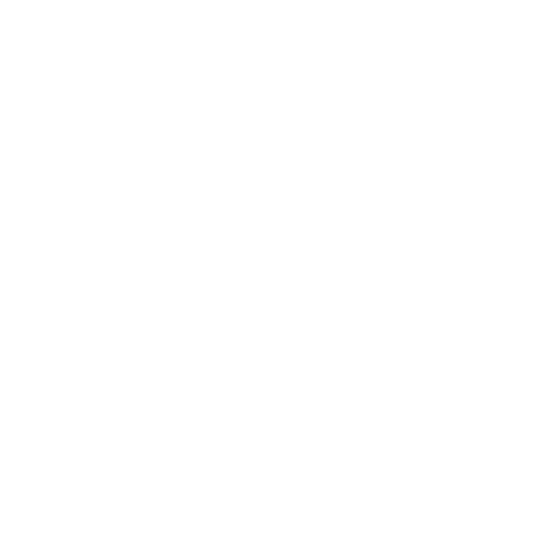




\section{International reporting obligations}

The LULUCF task force of the Netherlands Pollutant Release and Transfer Register reports on greenhouse gas emissions $\left(\mathrm{CO}_{2}, \mathrm{~N}_{2} \mathrm{O}, \mathrm{CH}_{4}\right)$ and $\mathrm{CO}_{2}$ removals caused by human activities in land use, land-use change and forestry in the Netherlands. These emissions are reported in the national greenhouse gas inventory of the Netherlands submitted to the UNFCCC and in the climate accounting under the Kyoto
Protocol. In addition, the task force also prepares additional mandatory LULUCF climate reports to the European Commission. These additional reports are used by the European Commission to gain further insight into the LULUCF emissions in the member states. The EU directives are designed to encourage member states to further reduce their emissions and promote carbon sequestration in the LULUCF sector.

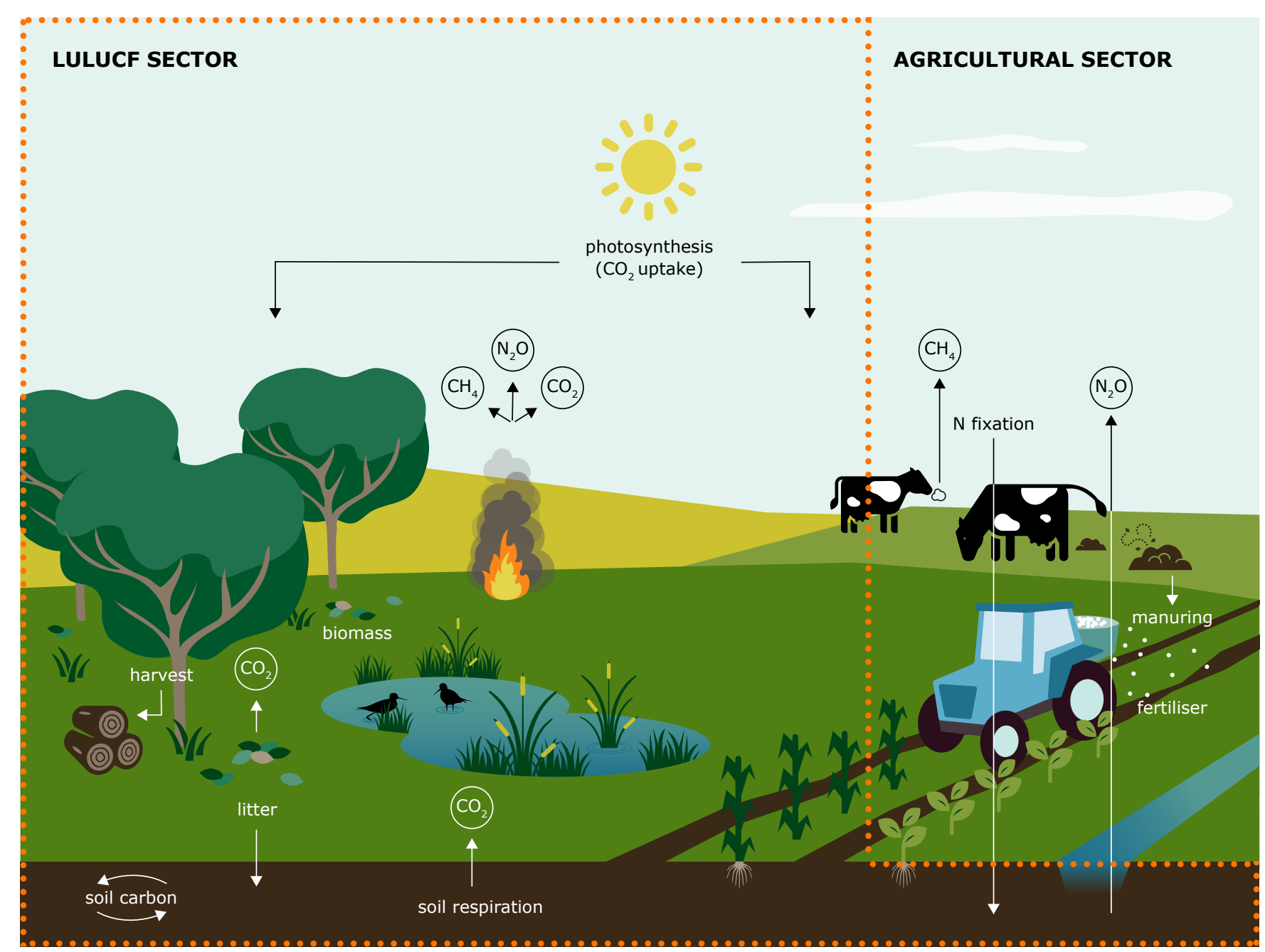

Figure 1: The LULUCF sector (bounded by the dotted orange line) in relation to the agricultural sector (based on IPCC 2006).

\section{Reading Guide}

\section{Introduction}

Emission Register

Methods \& Reporting

\section{Accounting Rules}

Greenhouse Gas Emissions

\section{Sources | colofon}

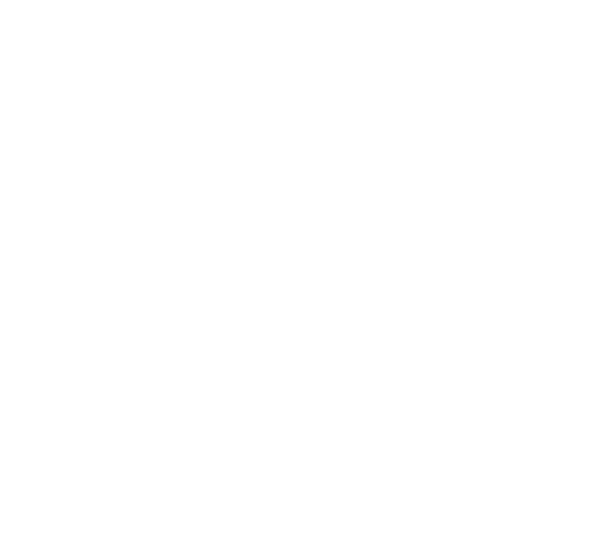


This reporting obligation also allows the Netherlands to monitor whether or not the targets for reducing greenhouse gas emissions are being met and to see where it stands in relation to other EU member states. In addition to these international reports, the LULUCF task force also provides data required under the National Climate Agreement.

\section{LULUCF sector in the Netherlands}

The greenhouse gas emissions from the LULUCF sector are the sum total from all types of land use, broken down into the following six land use categories: Forest Land, Cropland, Grassland, Wetlands, Settlements and Other Land. LULUCF reporting also includes the category Harvested Wood Products.

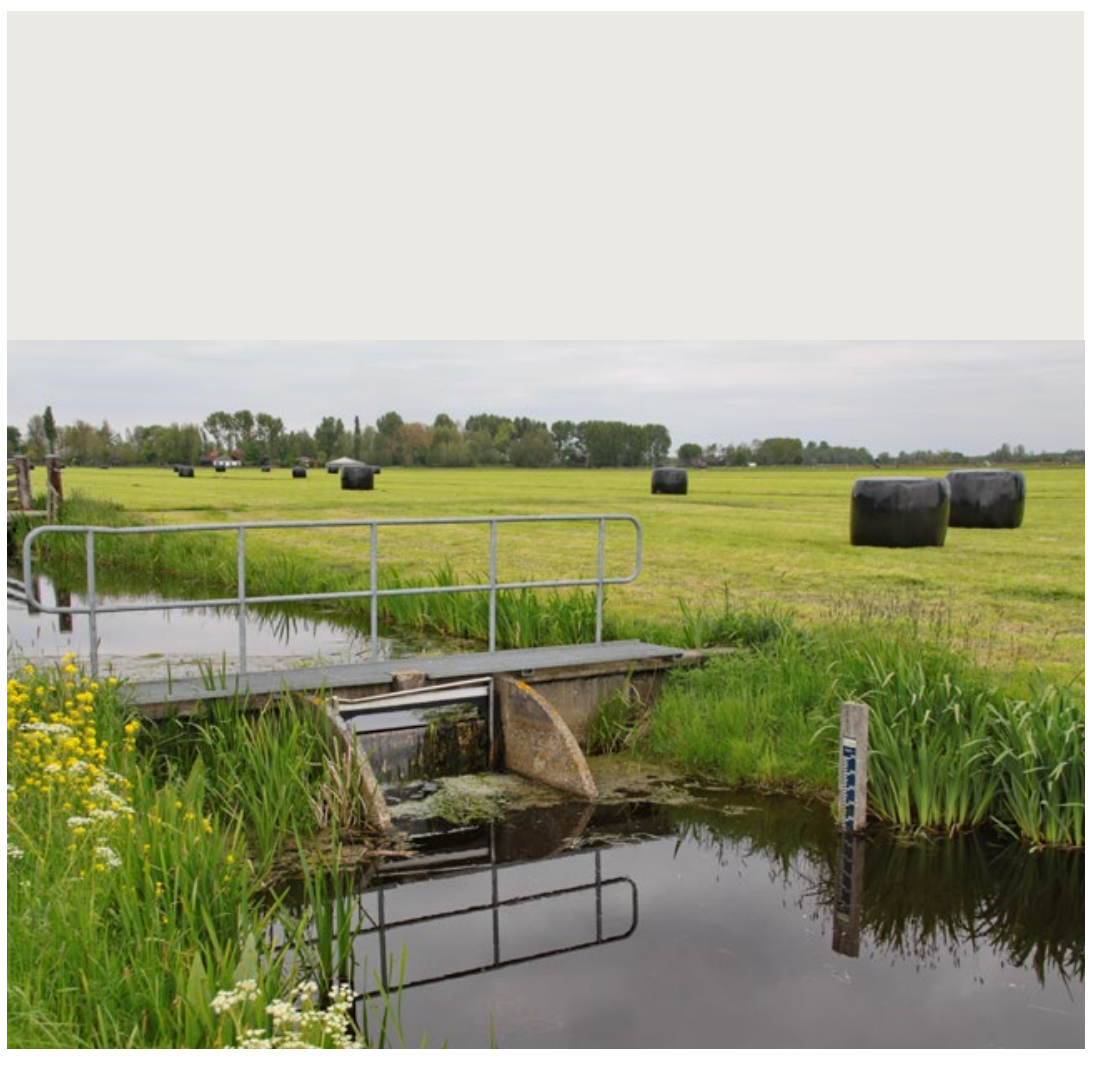

The high population density and low number of people per household mean that land uses in the Netherlands are continually under pressure from other sectors. The lowering of water tables for agricultural purposes leads to oxidation of peat, which releases large amounts of $\mathrm{CO}_{2}$. This is the largest source of greenhouse gas emissions within the LULUCF sector in the Netherlands. Forest Land and Land converted to Forest Land remove $\mathrm{CO}_{2}$ from the atmosphere, but forest fires result in emissions. Emissions are determined using area-wide data on land use, land-use change and soil type. In 2019 the LULUCF emissions were $2.4 \%$ lower (4.5 $\mathrm{Mt} \mathrm{CO}_{2}$ eq) than in 2018 (4.6 $\mathrm{Mt} \mathrm{CO}_{2}$ eq) and $25.5 \%$ lower than in the baseline year $1990\left(6.1 \mathrm{Mt} \mathrm{CO}_{2}\right.$ eq).

\section{About this publication}

This publication by the Statutory Research Tasks Unit for Nature \& the Environment explains how the reports on greenhouse gas emissions and removal of $\mathrm{CO}_{2}$ for land use, land-use change and forestry for the Netherlands Pollutant Release and Transfer Register are prepared, based on the situation in mid-2021. It focuses on the methods used and the assumptions behind the calculation of emissions and removals. This publication is aimed primarily at policymakers and researchers whose work involves the LULUCF sector.

The methodology we describe in this publication is reported annually in a WOt technical report. In this publication the land areas are based on 2017 data and the emission figures on 2019 data. More information on the structure of this publication and how to navigate through it is given in the Reading Guide.

If you have any questions or comments about this publication, please contact us.

\section{Reading Guide}

\section{Introduction}

\section{Emission Register}

Methods \& Reporting

\section{Accounting Rules}

Greenhouse Gas Emissions

\section{Sources | colofon}

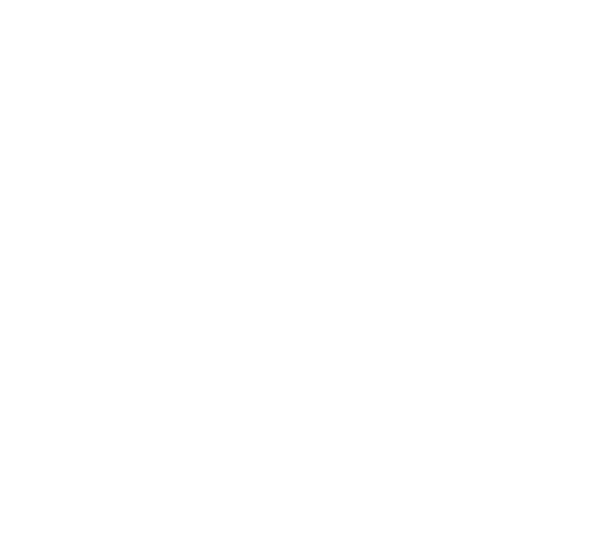




\section{Pollutant Release and Transfer Register}

\section{LULUCF reporting in the Netherlands is the responsibility of the Pollutant Release and Transfer Register. In this chapter we describe how this is organised.}

Since the beginning of the 1970s the Pollutant Release and Transfer Register (PRTR, Dutch: Emissieregistratie) has been the Dutch government's implementing agency for registering emissions of environmentally harmful substances to the air, water and soil. Environmentally harmful substances pose a threat to the health and vitality of plants, animals and humans. Information is collected on about 375 substances relevant to Dutch environmental policy. Data on all relevant Dutch emission sources are inventoried, checked and registered in a central database. The PRTR provides the emissions data needed to inform Dutch environmental and climate policies. In addition, the PRTR keeps track of the Netherlands' compliance with international climate obligations (UNFCCC, Kyoto Protocol) and guidance on large scale air pollution (NECD, Gothenburg Protocol). The emissions data are publicly available from www.emissieregistratie.nl.

\section{PRTR Consortium}

The PRTR is a consortium of various knowledge organisations commissioned by the Ministries of Infrastructure and Water Management (IenW), Economic Affairs and Climate Policy (EZK), and Agriculture, Nature and Food Quality (LNV) (see Figure 2). The National Institute for Public Health and the Environment (RIVM) is the lead executive agency and is responsible for coordinating and carrying out the collection and reporting of Dutch emissions data and for making these data available. The PRTR Consortium is a partnership of the participating institutes, which operate jointly on behalf of the ministries. The RIVM works with Statistics Netherlands (CBS), PBL Netherlands Environmental Assessment Agency, Deltares and Wageningen University \& Research (WUR). These partner institutes are responsible for the quality and timely delivery of the substantive parts of the reports.

\section{WEM and task forces}

The operational arm of the PRTR consists of the Working Group on Emission Monitoring (WEM) and several task forces, including one for LULUCF. They compile the emissions data and supply them to the central database. In addition, they perform quality checks on the data and suggest methodological improvements. There is a task force for each sector which determines the emissions in the sector according to the best available and agreed methods. Advisers at the partner institutes complement the sector knowledge of the task force chairs with expertise on data quality and on current and upcoming policy. The task force chairs meet in the WEM to identify and resolve substantive and operational issues in the task forces. The members of the LULUCF task force work at WUR, the Netherlands Environmental Assessment Agency (PBL) and the National Institute for Public Health and the Environment (RIVM).

\section{NIE}

International reporting obligations, such as under the UNFCCC and the Kyoto Protocol, require that countries regularly report their greenhouse gas emissions. The Ministry of Economic Affairs and Climate Policy has designated the Netherlands Enterprise Agency (RVO) as the National Inventory Entity (NIE). RVO is therefore not a partner institute. But as

\section{Reading Guide}

\section{Introduction}

\section{Emission Register}

Methods \& Reporting

\section{Accounting Rules}

Greenhouse Gas Emissions

\section{Sources | colofon}

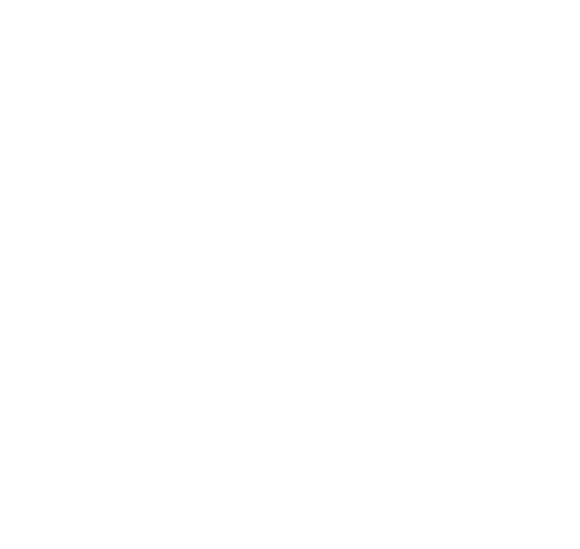


an independent entity, it is ultimately responsible for the National System for monitoring and reporting greenhouse gas emissions and guarantees the quality and timely production of these reports. In the WEM the Netherlands Enterprise Agency works as an adviser with the other parties on these issues.

\section{Quality control and independence}

The task forces are responsible for the delivery and quality control of emissions data. To ensure the independence of the emissions data, the commissioning ministries are not permitted to make any substantive input to the process. At the request of the head of the PRTR, the task forces approve the emissions data and the head of the PRTR aggregates all the data into a single dataset. The partner institutes then approve the dataset and commit to using these data - which have been agreed upon and with which the Netherlands meets its national and international reporting obligations - in publications and their other work. This procedure involving the PRTR consortium ensures that Dutch emissions data command broad unequivocal support.

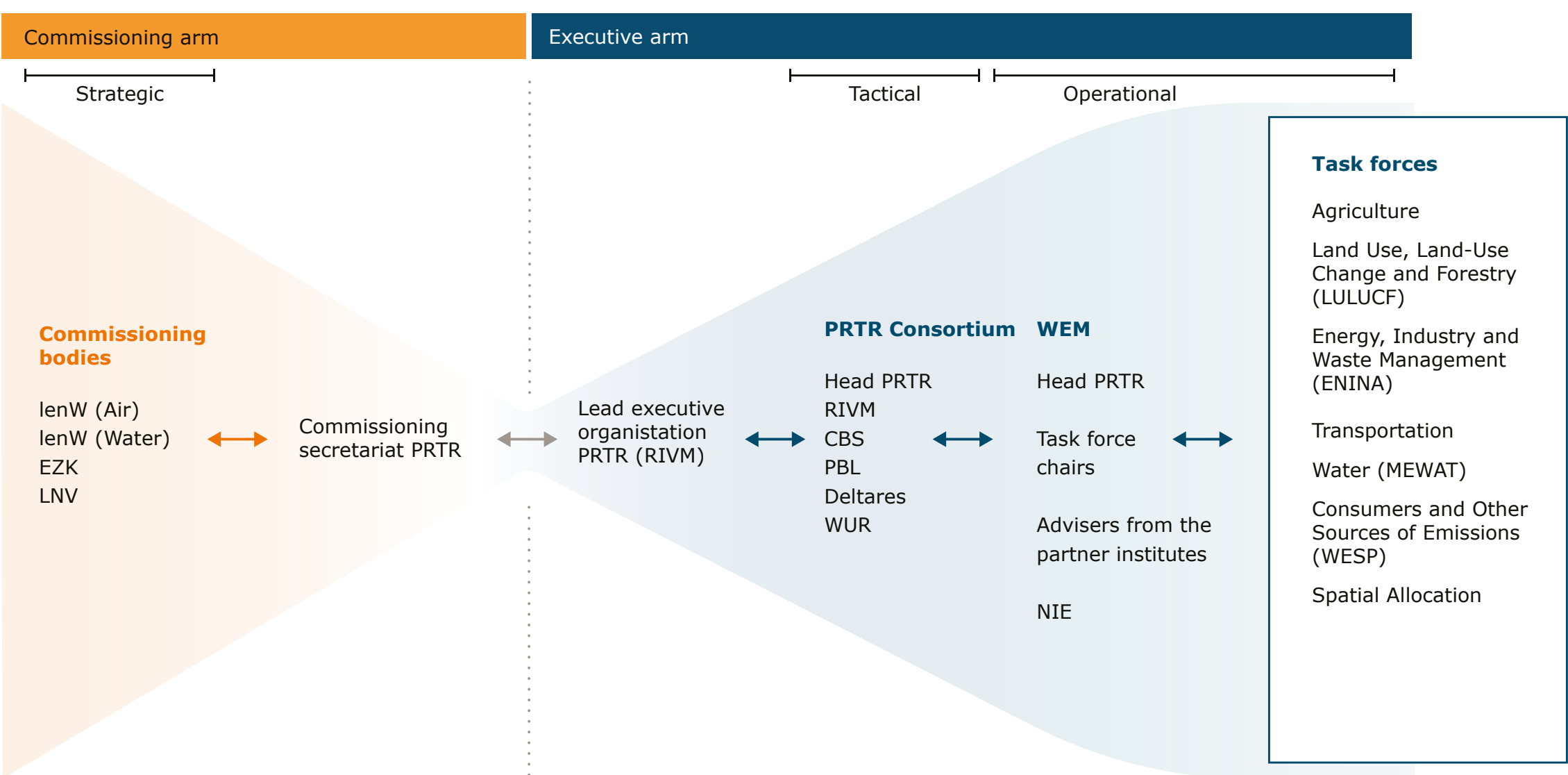

Figure 2: Diagram showing the organisation of the Pollutant Release and Transfer Register.

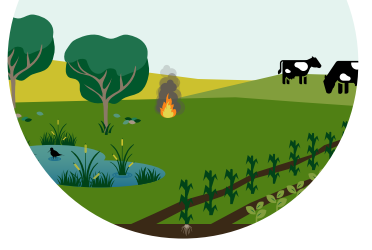

\section{Reading Guide}

\section{Introduction}

\section{Emission Register}

Methods \& Reporting

\section{Accounting Rules}

Greenhouse Gas Emissions

\section{Sources | colofon}

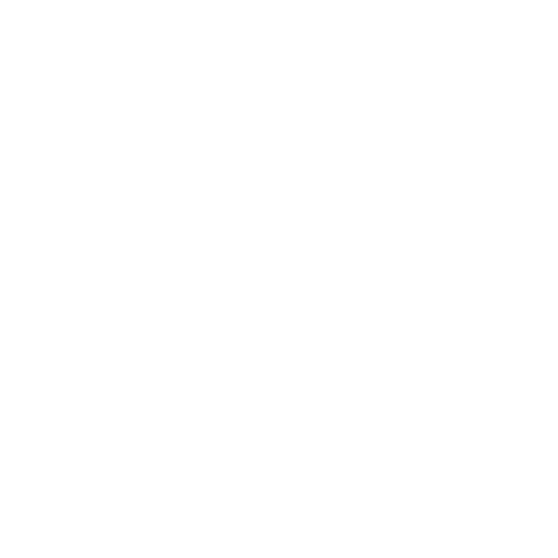




\section{Methods and Reporting}

Like other parties that report to the UN Climate Convention, the Netherlands must be transparent about the method it uses to determine its annual greenhouse gas emissions. The Netherlands has chosen to do this in the form of annual methodology reports. These reports also serve as a quality control and management system. In this chapter we explain the general LULUCF methodology and the various reporting requirements

The LULUCF sector makes a distinction between the annual reporting to the UNFCCC and how the country's climate performance is calculated and presented in its climate accounting, which is explained in the Accounting Rules chapter. Information on the greenhouse gas emissions and removals reported for the LULUCF sector is given in the Greenhouse Gas Emissions chapter. This is followed by chapters on each of the land use categories (Forest Land, Cropland, Grassland, Wetlands, Settlements and Other Land) in which we give a more detailed account of the definitions, methods used and the data on land areas and emissions per land use category.

\section{Method}

\section{Land use map}

The Dutch LULUCF methodology covers the entire land area of the Netherlands. Land use and land-use changes have been mapped for successive periods: 1970-1990, 1990-2004, 2004-2009, 2009-2013 and 2013-2017

(see Figure 3). The land-use map for the period 2017-2021 is still in preparation. The changes are clearly visible when the land use maps for the different periods are laid over each other. The LULUCF land-use maps show the six land-use categories: Forest Land, Cropland, Grassland,

Wetlands, Settlements and Other Land.
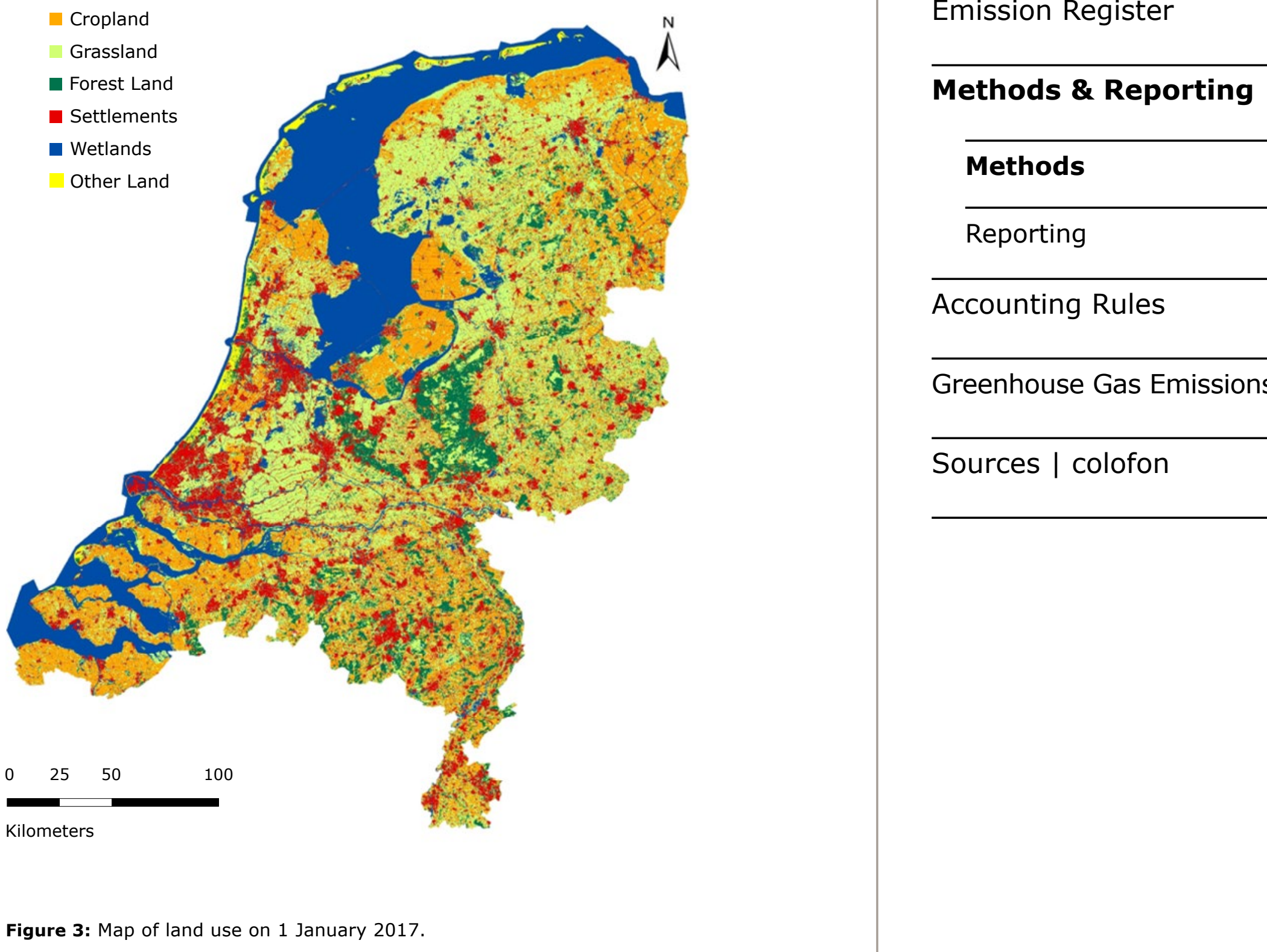
The land-use areas and changes in these areas during the period 2013-2017 are given in Table 1 (shows areas in hectares) and Table 2 (shows the changes between land use categories). Tables for previous periods are available in the annual methodology reports.

The land-use maps are supplemented with data from two soil maps, one from 1977 and a revised map from 2014 on which the areas of peat soils and peaty soils have been updated.

These maps and data are used to monitor land-use changes across the different soil types. In recent decades much peat has disappeared because groundwater levels have been lowered to facilitate agricultural uses, as a result of which soil water has drained from the soil pores and the peat has come into contact with oxygen $\left(\mathrm{O}_{2}\right)$ and oxidised, leading to emissions of $\mathrm{CO}_{2}$. This is the biggest source of emission in the LULUCF sector. Peat soils are therefore gradually turning into peaty soils and finally, when all the peat has oxidised, to mineral soils. This process is also accompanied by soil subsidence, which can be up to as much as a few centimetres each year.

\section{Calculating the sequestration and removal of} greenhouse gases

For all land-use changes and land-use types it is known how much greenhouse gas is released and how much is stored in the soil and in living biomass (e.g. trees). A calculation model (LASSO) links the information on land use and land-use change to the information on greenhouse gas emissions and storage. The model calculates how much

\begin{tabular}{|c|c|c|c|c|c|c|c|}
\hline $2013 \downarrow \quad 2017 \rightarrow$ & Forest Land & Cropland & Grassland & Wetlands & Settlements & Other Land & Total \\
\hline (Min) Forest Land & 356,631 & 1,662 & 11,357 & 804 & 4,886 & 404 & 375,743 \\
\hline Cropland & 901 & 762,447 & 170,428 & 1,674 & 8,865 & 24 & 944,340 \\
\hline Grassland & 5,959 & 103,321 & $1,216,743$ & 9,331 & 30,495 & 1,435 & $1,367,284$ \\
\hline Wetlands & 837 & 291 & 6,908 & 807,284 & 4,417 & 2,736 & 822,474 \\
\hline Settlements & 1,034 & 2,582 & 22,082 & 1,559 & 578,065 & 191 & 605,512 \\
\hline$\Leftrightarrow$ Other Land & 215 & 7 & 769 & 1,399 & 429 & 34,838 & 37,656 \\
\hline Total & 365,577 & 870,310 & $1,428,287$ & 822,052 & 627,156 & 39,628 & $4,153,009$ \\
\hline
\end{tabular}

Table 1: Matrix of land use and land-use change in hectares for the period 2013-2017. The columns give the land use per category in $2017(\rightarrow)$, with conversions to that category since $2013(\boldsymbol{\Psi})$; the rows give the land use per category in 2013 . 
greenhouse gas is released each year and how much is stored as a result of land use and land-use change across the whole of the Netherlands. The model uses the prescribed IPCC calculation methods, which are the same for every country. However, new scientific insights may lead to changes in certain values and calculation methods.

\section{Carbon stocks in mineral soils}

For mineral soils (such as sandy soils and clay soils) we calculate the $\mathrm{CO}_{2}$ emissions for all land use categories based on the IPCC Tier 2 approach. This involves calculating the soil carbon stock from the reference amount of carbon in the soil and a number of factors that determine land use, tillage and supply of organic carbon to the soil. To do this, the soil data from the LSK (Landelijke Steekproef Kaarteenheden), a national sample survey of soil map units, were reorganised into new combinations of land use and soil type. The land use at each of the LSK sample locations at the time of sampling is known. The soil types recorded for each of these sample points were reclassified into 11 main soil types which represent the main variation in soil carbon stocks in the Netherlands. The average soil carbon stocks for each of these new combinations were then calculated.
However, the LSK only contains data on Forest Land, Cropland and Grassland. For the remaining land use types estimates were made using the IPCC guidelines of 2006 .

The estimates were based on the following assumptions: - for conversion to the Settlements category: $50 \%$ of the area is paved and has a soil carbon stock that is $80 \%$ of the carbon stock of the previous land use, and the remaining $50 \%$ consists of Grassland or Forest Land with a corresponding soil carbon stock;

- for Wetlands converted to or from Forest Land there is no change in the soil carbon stock;

- for the Other Land category the carbon stock is nil (conservative assumption).

In the current method the assumption is that after a land-use change the soil carbon stocks will gradually change over a period of 20 years to the average soil carbon stock of the new land use and soil types (see Figure 4). After 20 years equilibrium is reached and we assume that the soil carbon stocks do not change any more. This means that if the soil carbon stock declines, $\mathrm{CO}_{2}$ emissions will take place over this 20 year period. Similarly, an increase in soil carbon will result in $\mathrm{CO}_{2}$ removal.

In land use categories that do not change, the soil carbon stocks remain the same.
Reading Guide

\section{Introduction}

Emission Register

Methods \& Reporting

Methods

Reporting

\section{Accounting Rules}

Greenhouse Gas Emissions

\section{Sources | colofon}

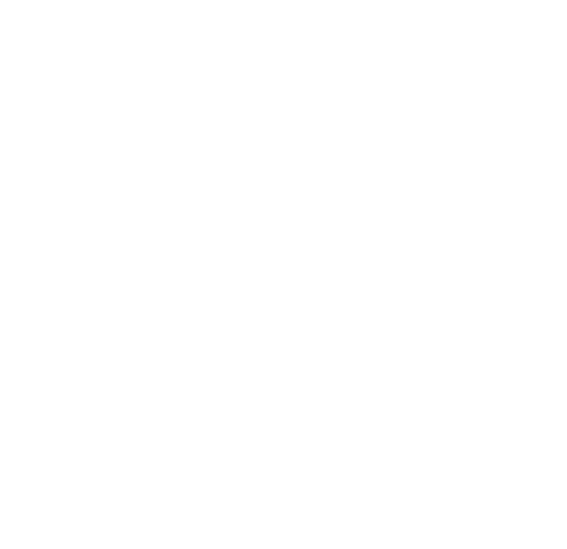




\section{Emissions from organic soils}

For emissions from organic soils, two types of soils are

identified: peat soils (a peat horizon of at least $40 \mathrm{~cm}$ in the

upper $120 \mathrm{~cm}$ of the soil) and peaty soils (a peat horizon

of at least $5-40 \mathrm{~cm}$ in the upper $80 \mathrm{~cm}$ of the soil). Based

on calculations of the effect of falling groundwater levels,

experts have determined the average annual emissions

from these soils in Cropland and Grassland with a primarily

agricultural use. For peat this is 19 tonnes $\mathrm{CO}_{2}$ per year and

for peaty soils 13 tonnes.

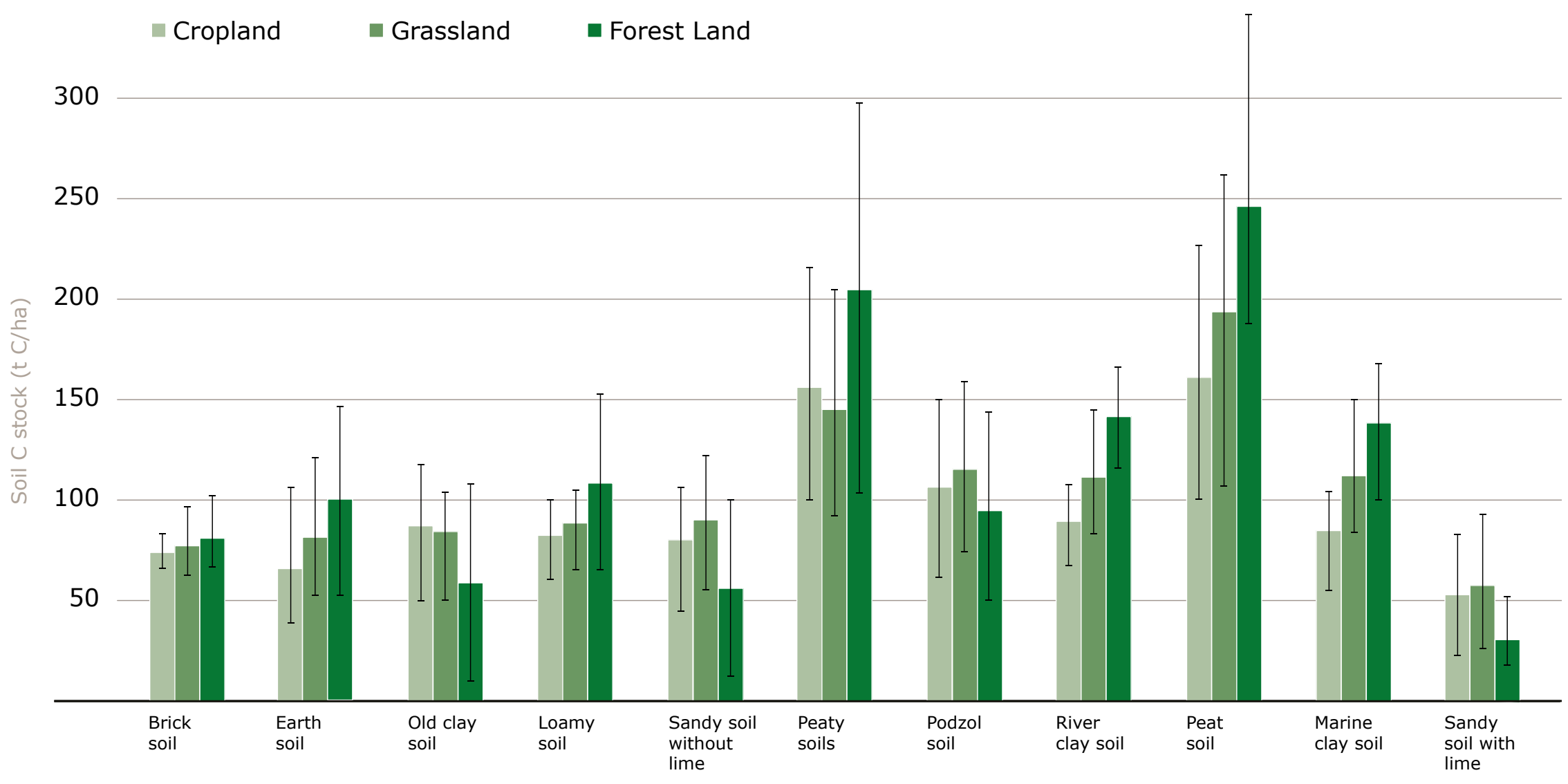

Figure 4: Average soil carbon stocks per land use in combination with soil type. The margins of error (I) indicate the standard deviations (source: Lesschen et al., 2012). 


\section{Reporting}

At the moment the Netherlands has four obligations to report on and/or maintain emissions accounts specifically for LULUCF:

1. UNFCCC reporting

2. Kyoto Protocol

3. EU Decision 529/2013

4. EU LULUCF Regulation $841 / 2018$

\section{UNFCCC reporting}

The emphasis in UNFCCC reporting is on monitoring greenhouse gas emissions. The Netherlands has to report national emissions and removals of greenhouse gases annually in a National Inventory Report (NIR) and in a Common

\section{Duration of reporting obligations}

- UNFCCC: annual reporting for the period from 1990 to t-2 (two years before the reporting year).

- Kyoto Protocol: accounting, two commitment periods: 2008-2012 (final accounts in 2014) and 2013-2020 (final accounts in 2022). EU Decision $529 / 2013$ follows the second commitment period for the Kyoto Protocol (2013-2020).

- EU LULUCF Regulation: 2021-2025 (accounting in 2027) and 2026-2030 (accounting in 2032).

Reporting Format (CRF) Table. The National Inventory Report 2021 (NIR2021) concerns greenhouse gas emissions during the period from 1990 to 2019. The emissions data in NIR2021 were calculated as described in the national methodology

\begin{tabular}{|c|c|c|c|c|c|c|}
\hline & Forest Land & Cropland & Grassland & Wetlands & Settlements & Other Land \\
\hline (19) Forest Land & $\begin{array}{l}\text { Forest Land } \\
\text { remaining } \\
\text { Forest Land }\end{array}$ & $\begin{array}{l}\text { Forest Land to } \\
\text { Cropland }\end{array}$ & $\begin{array}{l}\text { Forest Land to } \\
\text { Grassland }\end{array}$ & $\begin{array}{l}\text { Forest Land to } \\
\text { Wetlands }\end{array}$ & $\begin{array}{l}\text { Forest Land to } \\
\text { Settlements }\end{array}$ & $\begin{array}{l}\text { Forest Land to } \\
\text { Other Land }\end{array}$ \\
\hline Cropland & $\begin{array}{l}\text { Cropland to } \\
\text { Forest Land }\end{array}$ & $\begin{array}{l}\text { Cropland } \\
\text { remaining } \\
\text { Cropland }\end{array}$ & $\begin{array}{l}\text { Cropland to } \\
\text { Grassland }\end{array}$ & $\begin{array}{l}\text { Cropland to } \\
\text { Wetlands }\end{array}$ & $\begin{array}{l}\text { Cropland to } \\
\text { Settlements }\end{array}$ & $\begin{array}{l}\text { Cropland to } \\
\text { Other Land }\end{array}$ \\
\hline Grassland & $\begin{array}{l}\text { Grassland to } \\
\text { Forest Land }\end{array}$ & $\begin{array}{l}\text { Grassland to } \\
\text { Cropland }\end{array}$ & $\begin{array}{l}\text { Grassland } \\
\text { remaining } \\
\text { Grassland }\end{array}$ & $\begin{array}{l}\text { Grassland to } \\
\text { Wetlands }\end{array}$ & $\begin{array}{l}\text { Grassland to } \\
\text { Settlements }\end{array}$ & $\begin{array}{l}\text { Grassland to } \\
\text { Other Land }\end{array}$ \\
\hline Wetlands & $\begin{array}{l}\text { Wetlands to } \\
\text { Forest Land }\end{array}$ & $\begin{array}{l}\text { Wetlands to } \\
\text { Cropland }\end{array}$ & $\begin{array}{l}\text { Wetlands to } \\
\text { Grassland }\end{array}$ & $\begin{array}{l}\text { Wetlands } \\
\text { remaining } \\
\text { Wetlands }\end{array}$ & $\begin{array}{l}\text { Wetlands to } \\
\text { Settlements }\end{array}$ & $\begin{array}{l}\text { Wetlands to } \\
\text { Other Land }\end{array}$ \\
\hline Settlements & $\begin{array}{l}\text { Settlements to } \\
\text { Forest Land }\end{array}$ & $\begin{array}{l}\text { Settlements to } \\
\text { Cropland }\end{array}$ & $\begin{array}{l}\text { Settlements to } \\
\text { Grassland }\end{array}$ & $\begin{array}{l}\text { Settlements to } \\
\text { Wetlands }\end{array}$ & $\begin{array}{l}\text { Settlements } \\
\text { remaining } \\
\text { Settlements }\end{array}$ & $\begin{array}{l}\text { Settlements to } \\
\text { Other Land }\end{array}$ \\
\hline Other Land & $\begin{array}{l}\text { Other Land to } \\
\text { Forest Land }\end{array}$ & $\begin{array}{l}\text { Other Land to } \\
\text { Cropland }\end{array}$ & $\begin{array}{l}\text { Other Land to } \\
\text { Grassland }\end{array}$ & $\begin{array}{l}\text { Other Land to } \\
\text { Wetlands }\end{array}$ & $\begin{array}{l}\text { Other Land to } \\
\text { Settlements }\end{array}$ & $\begin{array}{l}\text { Other Land remai- } \\
\text { ning Other Land }\end{array}$ \\
\hline
\end{tabular}

Table 2: Categories of land use and land-use change used for LULUCF reporting. Reporting is per land use category listed above each column. 
report. Methodology reports are drawn up by experts from the PRTR in close cooperation with the Netherlands Enterprise Agency. In addition to the annual reports, countries have to submit a Biennial Report every two years and a National Communication every four years. Both of these are very policy-oriented. The NIR must be prepared in line with UNFCCC guidance and the 2006 IPCC Guidelines for National Greenhouse Gas Inventories.

The matrix of land use and land-use change categories used for LULUCF reporting is shown in Table 2. After a land-use change, the land is reported for a number of years (usually 20 ) under the subcategory 'Land converted to'. This 20 years is a standard transition period needed to stabilise the changes in soil carbon stocks in mineral soils. After this transition period the land and associated greenhouse gas emissions and removals are included in the Land remaining Land category.

The emission factors for land use categories are based on the changes in carbon stocks of the following carbon pools:

- above-ground living biomass,

- below-ground living biomass,

- litter (only forests; for other land use categories, dead organic matter),

- dead wood (only forests; for other land use categories dead organic matter),

- soil organic carbon (mineral and organic soils listed separately).
For these carbon pools the changes in carbon stocks are converted to net $\mathrm{CO}_{2}$ emissions (if carbon stocks decrease) or removals (if carbon stocks increase). $\mathrm{CO}_{2}$ removals are reported as negative $\mathrm{CO}_{2}$ emissions.

Several other direct and indirect emissions have to be reported under LULUCF:

- direct nitrous oxide $\left(\mathrm{N}_{2} \mathrm{O}\right)$ emissions from nitrogen inputs to managed soils (only if this has not already been reported under agriculture);

- emissions and removals from drainage, rewetting and other management of organic and mineral soils;

- direct nitrous oxide $\left(\mathrm{N}_{2} \mathrm{O}\right)$ emissions from nitrogen mineralisation/immobilisation associated with loss/gain of soil organic matter resulting from changes of land use or management of mineral soils:

- indirect nitrous oxide $\left(\mathrm{N}_{2} \mathrm{O}\right)$ emissions from managed soils (resulting from atmospheric deposition and nitrogen leaching and run-off from managed soils);

- $\mathrm{CO}_{2}, \mathrm{CH}_{4}$ and $\mathrm{N}_{2} \mathrm{O}$-emissies as a result of controlled burning of biomass or wildfires.

The carbon balance for living biomass in Forest Land remaining Forest Land is based on data on supplementary growth and stock volumes of wood from the Dutch forest inventories (NFIs). Information on dead wood is also obtained from the NFIs. Every four years a new forest inventory is included in the LULUCF system.

\section{Kyoto Protocol}

The emphasis in Kyoto Protocol reporting is on reducing greenhouse gas emissions. The Netherlands reported for the first time in 2010, when it reported only on the activity 'afforestation and reforestation and deforestation'.
Reading Guide

\section{Introduction}

Emission Register

Methods \& Reporting

Methods

\section{Reporting}

\section{Accounting Rules}

Greenhouse Gas Emissions

\section{Sources | colofon}

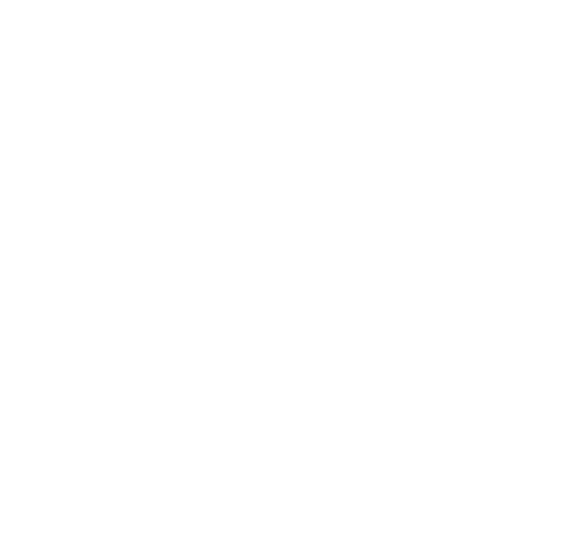




\section{EU Decision 529/2013}

Under the EU Greenhouse Gas Monitoring Mechanism Regulation (MMR) the Netherlands reports on trends in greenhouse gas emissions and changes in climate policy. The Netherlands is required to submit an integrated National Energy and Climate Plan for the period 2021-2030. In March 2023 and every two years thereafter the EU member states must report their progress on implementing the plans.

\section{EU LULUCF Regulation 841/2018}

EU LULUCF Regulation 841/2018 contains accounting rules for greenhouse gas emissions and reductions for the various land use categories in the LULUCF sector. EU member states have to submit a National Forestry Accounting Plan (NFAP) that includes the reference level for forests and provides a description of its determination.
Reading Guide

\section{Introduction}

Emission Register

Methods \& Reporting

Methods

a target for the LULUCF sector of an improvement of $1.5 \mathrm{Mt} \mathrm{CO}_{2}$ eq from the 1990 reference year. This target corresponds with the LULUCF Regulation. To achieve it, the organic matter contents in land use categories or during land-use changes must be maintained and/or increased. There are several ongoing programmes that investigate the effect of measures on soil carbon stocks. For example, the Smart Land Use (Slim Landgebruik) programme investigates how Dutch soils can contribute towards this target and is looking into a methodology for carbon credits. Carbon credits (tradeable or non-tradeable) are certificates that guarantee the sequestration of a certain amount of soil carbon.

\section{Reporting}

\section{Accounting Rules}

Greenhouse Gas Emissions

\section{Sources | colofon}

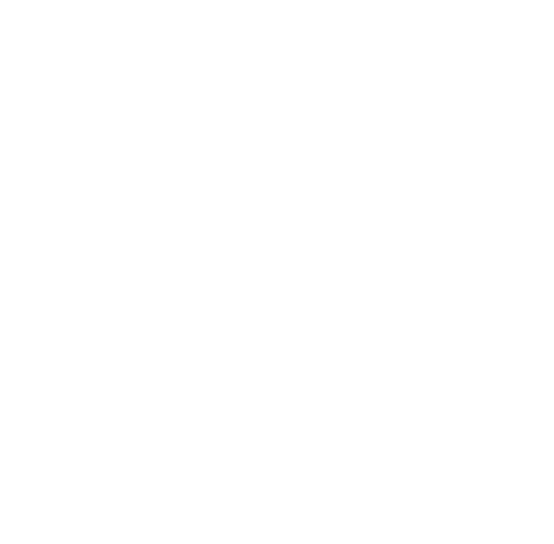




\section{Accounting Rules}

Total greenhouse gas emissions are reported to the United Nations Framework Convention on Climate Change (UNFCCC) in the National Inventory Report of the Netherlands. Performance targets have been agreed upon in order to achieve the stated emission reductions. To this end, additional accounting rules have been drawn up that determine whether and how each part of the emissions and removals of $\mathrm{CO}_{2}$ count towards the agreed climate targets under the Kyoto Protocol and the EU LULUCF Regulation (841/2018). This chapter explains the main accounting rules for these reports.
Kyoto Protocol

In 1997 the Kyoto Protocol introduced legally binding obligations under international law requiring committed developed countries to reduce their greenhouse gas emissions in the period 2008-2012. In 2012 the Kyoto Protocol was amended to include new commitments for the period 2013-2020 (the Doha Amendment). Under the Kyoto Protocol, rules have been agreed on how emissions and removals of $\mathrm{CO}_{2}$ are to be assessed. Whereas most other sectors have reduction targets relative to a baseline year (1990), the rules for the LULUCF sector depend on which activity is being assessed (deforestation, afforestation,
Reading Guide

Introduction

Emission Register

Methods \& Reporting

\section{Accounting Rules}

Greenhouse Gas Emissions

\section{Sources | colofon}

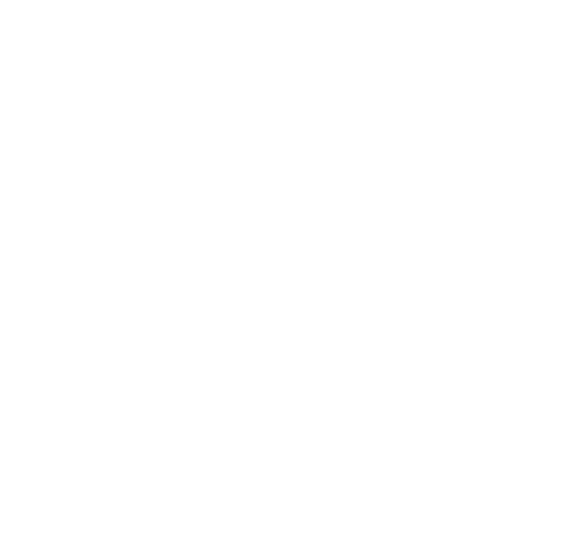

\begin{tabular}{|c|c|c|c|c|}
\hline UNFCCC & Kyoto Protocol (2013-2020 & & EU 2018/841 & \\
\hline Categories & Categories & Accounting rules & Categories & Accounting rules \\
\hline (4) Forest Land & $\begin{array}{l}\text { Aff/Reforestation } \\
\text { Deforestation } \\
\text { Forest management }\end{array}$ & $\begin{array}{l}\text { Mandatory, gross-net } \\
\text { Mandatory, related } \\
\text { to reference level }\end{array}$ & $\begin{array}{l}\text { - Afforested land } \\
\text { - Deforested land } \\
\text { - Managed forest land }\end{array}$ & $\begin{array}{l}\text { Mandatory, gross-net } \\
] \text { Mandatory, related } \\
\text { to reference level }\end{array}$ \\
\hline $\begin{array}{l}\text { - Cropland } \\
\text { - Grassland }\end{array}$ & - Gropland management & & $\begin{array}{l}\text { - Managed cropland } \\
\text { - Managed grassland } \\
\end{array}$ & $\begin{array}{l}\text { Mandatory, relative to } \\
\text { baseline period 2005-2009 }\end{array}$ \\
\hline $\begin{array}{l}\text { - Wetlands } \\
\text { - Settlements } \\
\text { o Other Land }\end{array}$ & Wevegetation & to 1990 & - Managed wetlands & $\begin{array}{l}\text { Voluntary, relative to } \\
\text { baseline period 2005- } \\
2009 \text { (mandatory from } \\
\text { 2026) }\end{array}$ \\
\hline
\end{tabular}

Figure 5: The reporting obligations (under UNFCCC) and accounting provisions under the second commitment period of the Kyoto Protocol and EU LULUCF Regulation 2018/841. 
forest management, cropland management or grazing land management; see Figure 5). Parties are required to report and provide accounts on deforestation, afforestation and

forest management. The other Kyoto Protocol activities are voluntary and at the start of the second commitment period (2013-2020) parties had to decide whether or not they would include them in their Kyoto climate accounting. The Netherlands chose to include only the mandatory (forest) categories in its accounts. Besides the mandatory additional reporting for LULUCF under the Kyoto Protocol, the EU also collects information on the other Kyoto Protocol activities.

Article 3.2 of EU LULUCF Decision 529/2013 requires member states, in addition to the NIR, to report non-

binding figures for cropland management and grazing land management.

\section{Paris Agreement and EU Regulation 2018/841}

The emission reductions set down in the Paris Agreement (PA) apply to the period 2021-2030. Parties to the PA are required to state their performance targets in Nationally Determined Contributions (NDC). The ultimate goal of the PA is to achieve a balance between greenhouse gas emissions and removals in the second half of this century. The parties to the PA have a certain degree of choice regarding the measures they can adopt to achieve this.

Performance will be assessed against the NDC, but again, parties have a certain degree of choice in how they assess and account for the LULUCF sector. EU member states have a joint NDC, the three main elements of which are the EU Emissions Trading Scheme (for energy and heavy industry), the 'effort sharing' and LULUCF. In the Effort Sharing Regulation (ESR) the member states have set a common target for the categories covered, but the allocation of the reductions that need to be made is different for each of the member states on the basis of previously agreed criteria. In 2018 agreements were also made on how the EU member states should account for reductions in greenhouse gas emissions and increases in removals from LULUCF (in EU Regulation 2018/841). These incorporate some of the experiences and rules from the Kyoto Protocol, but applied more directly to the UNFCCC categories. The land-use activities are derived directly from the land-use categories.

\section{Accounting under EU LULUCF Regulation 841 and the}

\section{Paris Agreement}

Land-use categories and land-use changes are translated directly into a set of accounting categories (see box) for which different sets of accounting rules apply.

In the first compliance period (2021-2025) the LULUCF emissions accounts must include all land use categories except managed wetlands; inclusion of managed wetlands is not mandatory for this period.
Reading Guide

\section{Introduction}

Emission Register

Methods \& Reporting

\section{Accounting Rules}

Greenhouse Gas Emissions

\section{Sources | colofon}

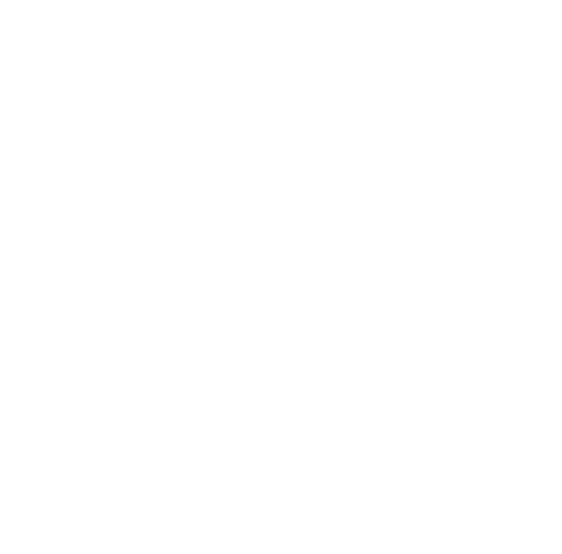


LULUCF emissions accounts for the second compliance period (2026-2030) must include all land use categories, including managed wetlands.

For afforested land and deforested land, total emissions and removals (sequestration) during the reporting period must

be included in the accounts. The net emissions are therefore a debit and net removals are a credit.

LULUCF emissions and removals from managed cropland, managed grassland and managed wetlands are discounted against the average emissions and removals for the land use categories during the baseline period 2005-2009. The difference determines the size of the credit (if emissions are lower or removals higher than in the baseline period) or the debit (if emissions are higher or removals lower than in the baseline period).

\section{Forest reference level}

In both reporting periods the managed forest land category, including Harvested Wood Products, is set off against a forest reference level ( $F R L)$. This FRL is an estimate of greenhouse gas removals (by carbon sequestration in forests). It takes account of age-related growth of the existing forest on the assumption that the forest management regime is a continuation of the management during the historical reference period (2000-2009). The FRL and supporting description of its determination is set down in a National Forestry Accounting Plan (NFAP).

\section{Accounting categories}

1. Afforested land (ARL): land use reported as Cropland, Grassland, Wetlands, Settlements or Other Land converted to Forest land;

2. Deforested land (DL): land use reported as Forest land converted to Cropland, Grassland, Wetlands, Settlements or Other Land;

3. Managed forest land (MFL): land use reported as Forest Land remaining Forest Land;

4. Managed cropland (MCL): land use reported as:

- Cropland remaining Cropland

- Grassland, Wetlands, Settlements or Other Land converted to Cropland; or - Cropland converted to Wetlands, Settlements or Other Land

5. Managed grassland (MGL): land use reported as:

- Grassland remaining Grassland

- Cropland, Wetlands, Settlements or Other Land converted to grassland; or - Grassland converted to Wetlands, Settlements or Other Land;

6. Managed wetlands (MWL): land use indicated as:

- Wetlands remaining Wetlands;

- Settlement or Other Land converted to Wetlands; or

- Wetlands converted to Settlements or Other Land.
Reading Guide

Introduction

Emission Register

Methods \& Reporting

Accounting Rules

Greenhouse Gas Emissions

Sources | colofon

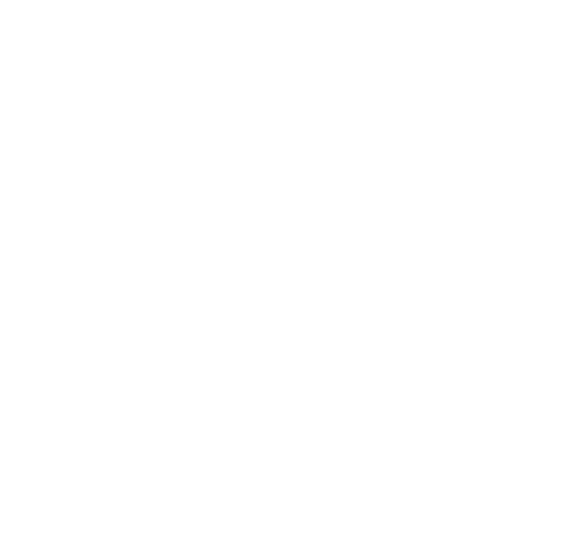




\section{Reference levels for managed cropland,}

\section{grassland and wetlands}

To calculate these reference levels we determine the average emissions for the baseline period 2000-2009 for the managed cropland, managed grassland and managed wetlands accounting categories. The task force calculates these average emission figures by combining the emission figures for the UNFCCC land use categories and land-use changes.

\section{Uncertainties in the calculations}

Greenhouse gas emissions are difficult to measure or calculate exactly. Uncertainties are inevitable. The PRTR estimates the level of uncertainty in the annual total greenhouse gas emissions at about 3\%, as determined by emission experts in an uncertainty analysis (according to IPCC Tier 1 - see box). Total Dutch greenhouse gas emissions therefore lie within a $95 \%$ confidence interval of between 183 and $194 \mathrm{Mt} \mathrm{CO}$ eq.

The uncertainty in the trend in emissions between the baseline year 1990 and 2017 is therefore estimated at about 2 percentage points. This means that the trend in emissions (a decrease of about 15\%) in that period lies within a $95 \%$ confidence interval of between $-13 \%$ and $-17 \%$

\section{IPCC Tier 1, 2 and 3}

A Tier represents a level of methodological complexity. Tier 1 is the basic method, Tier 2 is an intermediate method and Tier 3 is the most demanding in terms of complexity and data requirements. Tiers 2 and 3 are generally considered to be more accurate, provided sufficient data are available to develop, evaluate and apply a method at a higher level.

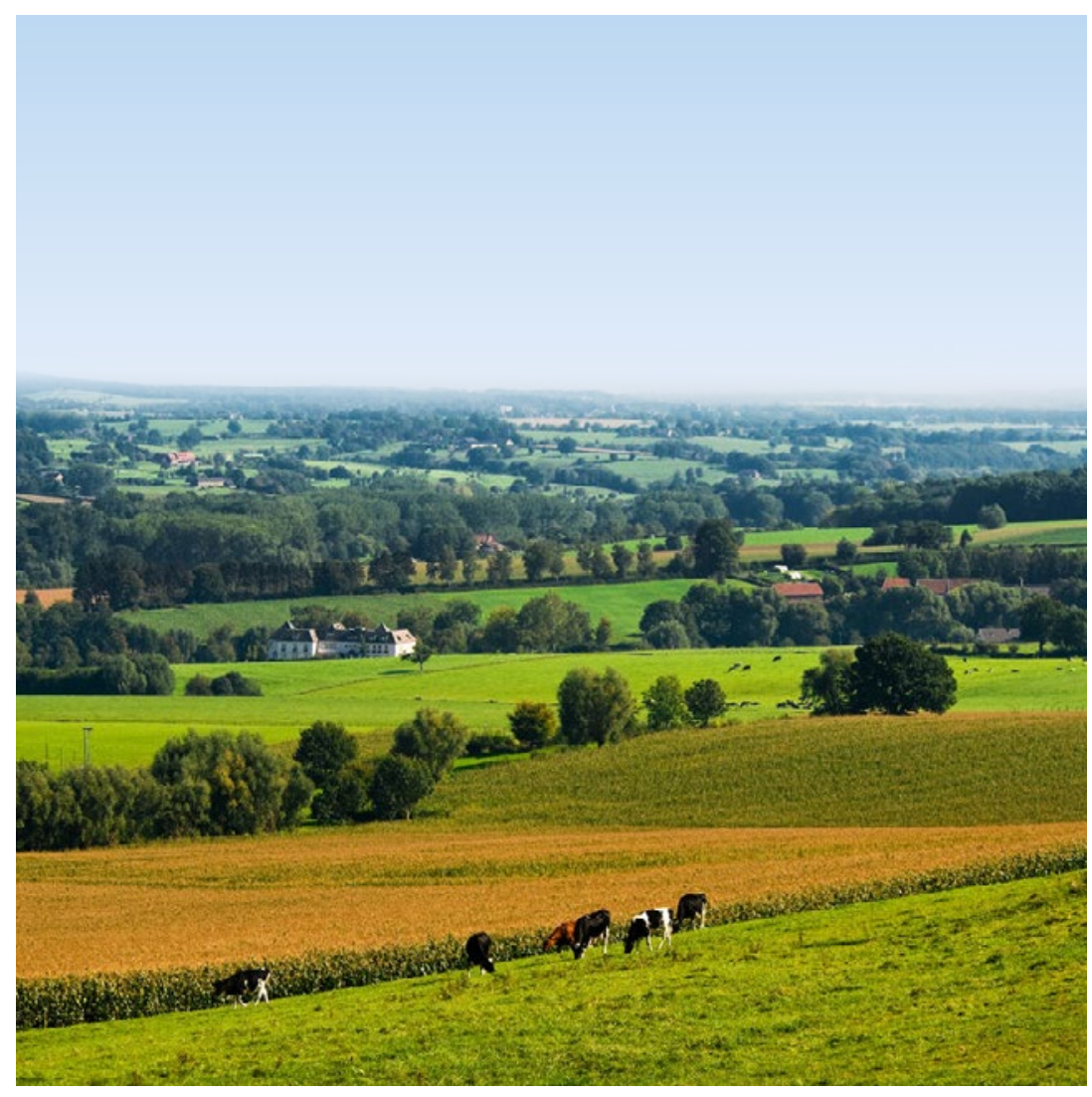

\section{Reading Guide}

\section{Introduction}

Emission Register

Methods \& Reporting

\section{Accounting Rules}

Greenhouse Gas Emissions

\section{Sources | colofon}

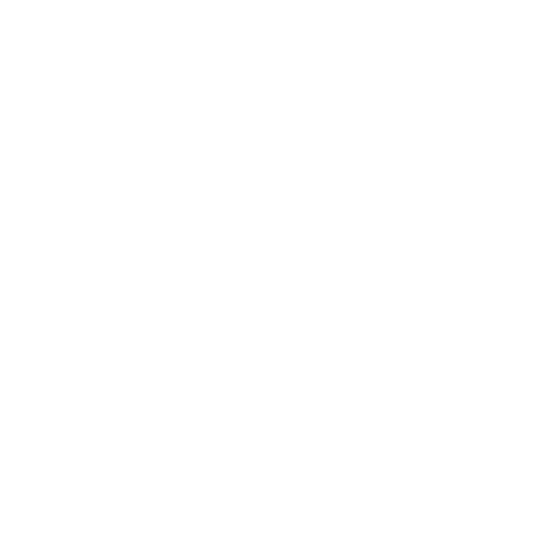




\section{Greenhouse Gas Emissions}

The LULUCF sector reports on greenhouse gas emissions and removals from land use, land-use change and forestry. This chapter presents the emissions and removals of the greenhouse gases $\mathrm{CO}_{2}, \mathrm{CH}_{4}$ and $\mathrm{N}_{2} \mathrm{O}$ for the entire LULUCF sector and per land use category.

Land use, land-use change and forestry have a major impact on the climate. Land-use change can lead to increased formation of greenhouse gases, but also to a reduction in greenhouse gases as a result of the uptake of atmospheric $\mathrm{CO}_{2}$. For example, deforestation results in additional emissions and planting forests leads to carbon sequestration. The LULUCF sector not only emits greenhouse gases, but also has a great potential for reducing greenhouse gas emissions, for example through carbon sequestration in biomass and soils. It is therefore essential to have a clear picture of emissions from the LULUCF sector

\section{Dutch LULUCF emissions}

Dutch LULUCF emissions in 2019 were 2.4\% lower (4.5 $\mathrm{Mt} \mathrm{CO}_{2}$ eq) than in 2018 (4.6 $\mathrm{Mt} \mathrm{CO}_{2}$ eq) and $25.5 \%$ lower than in the baseline year $1990\left(6.1 \mathrm{Mt} \mathrm{CO}_{2}\right.$ eq).

Most emissions are caused by peat oxidation and deforestation. $\mathrm{CH}_{4}$ emissions come from forest fires and wildfires. $\mathrm{N}_{2} \mathrm{O}$ emissions are caused mainly by working the soil during land-use changes and to a small extent by forest fires and wildfires. Table 3 shows the emissions and removals of $\mathrm{CO}_{2}, \mathrm{CH}_{4}$ and $\mathrm{N}_{2} \mathrm{O}$ for each land-use category in 2019. The following chapters give the emissions and removals for each of the land-use categories (Forest Land, Cropland Grassland, Wetlands, Settlements and Other Land) for the period 1990-2019.

\section{$\mathrm{CO}_{2}$ equivalents}

Greenhouse gases do not all have the same level of impact on the climate. To compare and add up the influence of the different greenhouse gases, $\mathrm{CH}_{4}$ and $\mathrm{N}_{2} \mathrm{O}$ emissions are converted to $\mathrm{CO}_{2}$ equivalents $\left(\mathrm{CO}_{2} \mathrm{eq}\right)$. One $\mathrm{CO}_{2}$ equivalent is equal to the emission of $1 \mathrm{~kg} \mathrm{CO}_{2}$. The emission of $1 \mathrm{~kg}$ nitrous oxide $\left(\mathrm{N}_{2} \mathrm{O}\right)$ is equal to $298 \mathrm{~kg} \mathrm{CO} 2$ equivalents and the emission of $1 \mathrm{~kg}$ methane $\left(\mathrm{CH}_{4}\right)$ is equal to $25 \mathrm{~kg} \mathrm{CO}$ equivalents.

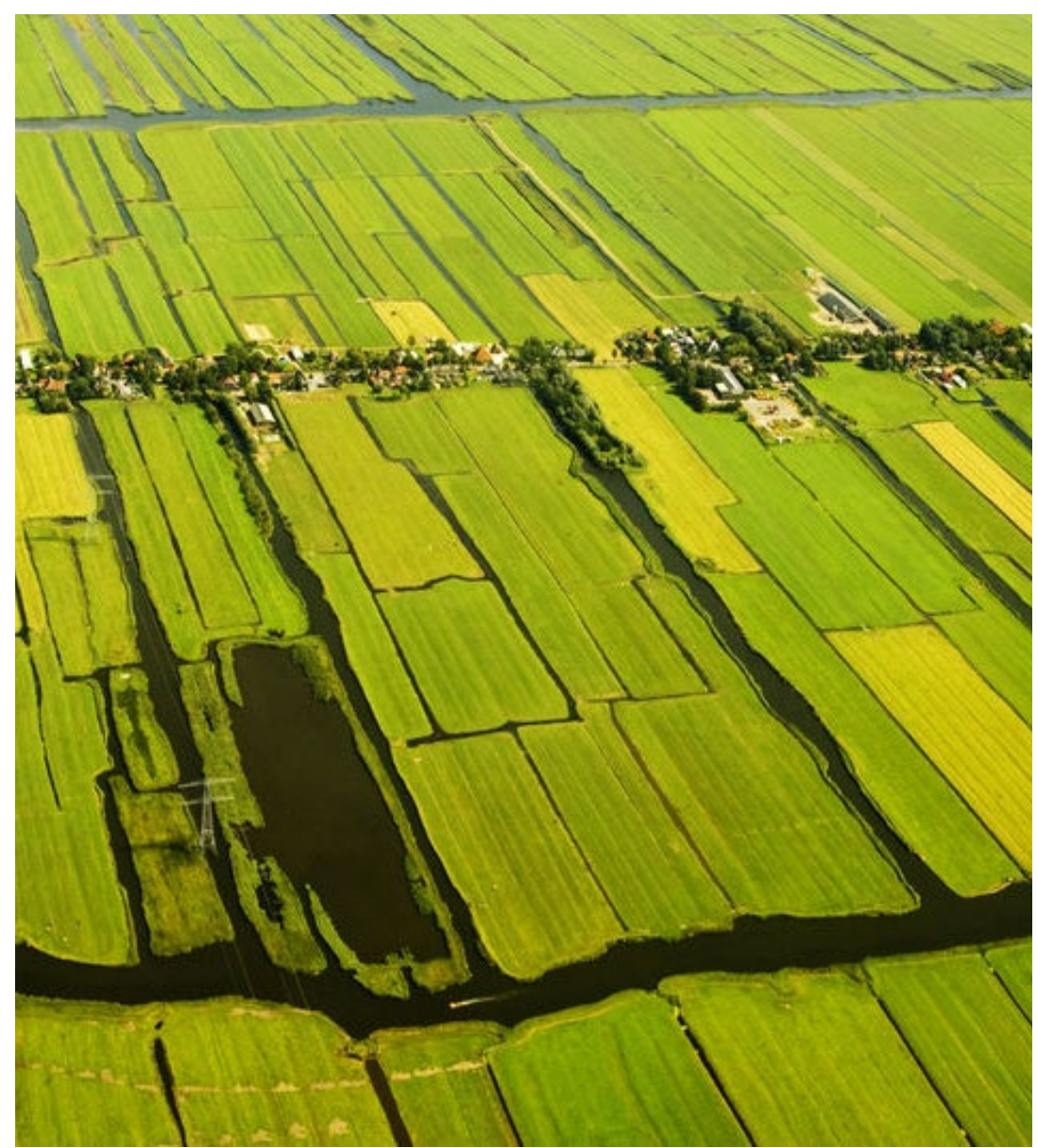

Reading Guide

Introduction

Emission Register

Methods \& Reporting

Accounting Rules

\section{Greenhouse Gas}

Emissions

\section{Sources | colofon}

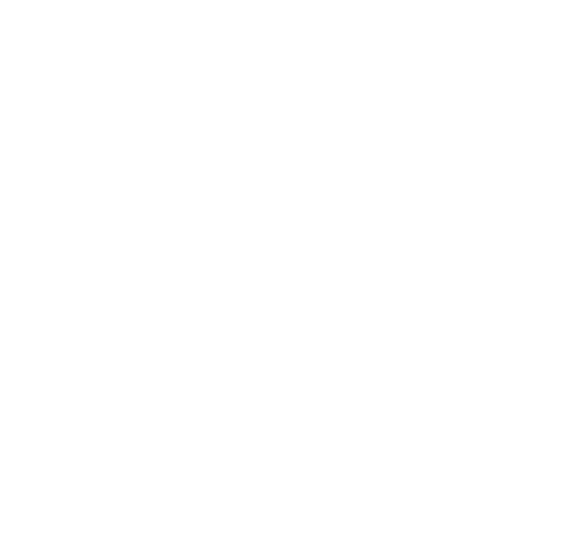


Table 3: Emissions and removals of $\mathrm{CO}_{2} \mathrm{CH}_{4}$ and $\mathrm{N}_{2} \mathrm{O}$ for the different LULUCF categories in 2019, from the CRF tables in the NIR 2021. Negative values indicate net removals; positive values indicate emissions. Forest Land, for example, removes $\mathrm{CO}_{2}$ from the atmosphere, whereas Cropland causes emissions. Empty cells indicate that there are no emissions in that category or that emissions have not been estimated and/or have been

reported elsewhere.

\begin{tabular}{|c|c|c|c|}
\hline & $\mathrm{CO}_{2}$ & $\mathrm{CH}_{4}$ & $\mathrm{~N}_{2} \mathrm{O}$ \\
\hline & \multicolumn{3}{|c|}{$(\mathrm{kt})$} \\
\hline Forest Land & $-1,844.60$ & 0.01 & 0.02 \\
\hline Forest Land remaining Forest Land & $-1,371.42$ & 0.01 & 0.00 \\
\hline Land converted to Forest Land & -473.18 & - & 0.01 \\
\hline Eid Cropland & $1,574.49$ & - & 0.17 \\
\hline Cropland remaining Cropland & 423.00 & - & - \\
\hline Land converted to Cropland & $1,151.49$ & - & 0.17 \\
\hline Grassland & $2,899.72$ & 0.00 & 0.03 \\
\hline Grassland remaining Grassland & $3,170.52$ & 0.00 & 0.00 \\
\hline Land converted to Grassland & -270.80 & - & 0.02 \\
\hline Wetlands & 25.04 & - & 0.01 \\
\hline Wetlands remaining Wetlands & -1.90 & - & 0.00 \\
\hline Land converted to Wetlands & 26.94 & - & 0.01 \\
\hline Settlements & $1,479.27$ & - & 0.09 \\
\hline Settlements remaining Settlements & 370.01 & - & - \\
\hline Land converted to Settlements & $1,109.26$ & - & 0.09 \\
\hline$(\Leftrightarrow)$ Other Land & 174.91 & - & 0.03 \\
\hline Other Land remaining Other Land & - & - & - \\
\hline Land converted to Other Land & 174.91 & - & - \\
\hline (@) Harvested Wood Products & 111.31 & - & - \\
\hline Total LULUCF & $4,420.13$ & 0.01 & 0.34 \\
\hline
\end{tabular}

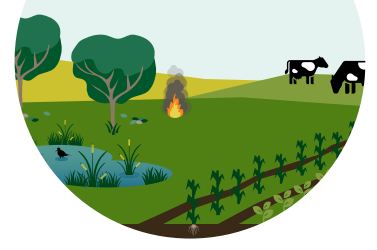

Reading Guide

Introduction

Emission Register

Methods \& Reporting

Accounting Rules

\section{Greenhouse Gas}

Emissions

Sources | colofon

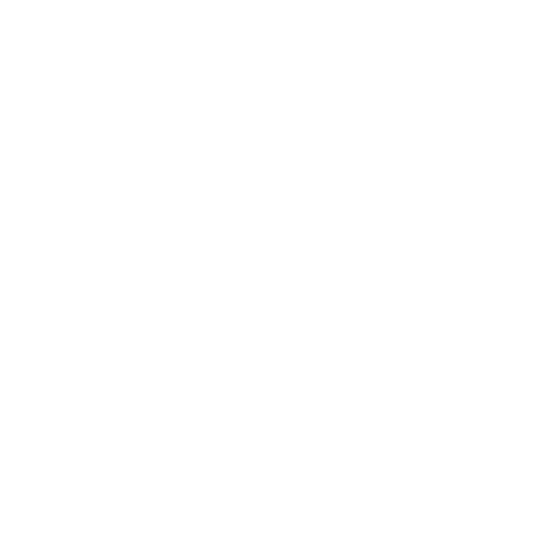




\section{Forest Land}

\section{Definition of land use category Forest Land}

Forest Land is all land with woody vegetation, now or expected in the near future (e.g. clear-cut areas to be replanted, young Afforestation areas). This is further defined as:

1. forests are patches of land exceeding 0.5 ha with a minimum width of $30 \mathrm{~m}$;

2. with tree crown cover of at least $20 \%$ or, if this is not the case, likely to be achieved at the particular site, and

3. tree height at least 5 metres, or, if this is not the case, likely to be achieved at the particular site.

This definition includes tree nurseries and seed orchards if they are part of a forest, windbreaks and forest paths and firebreaks as long as they are not wider than $6 \mathrm{~m}$.

The definition of Forest Land does not include afforestation that is part of an agricultural production system, such as fruit orchards and agroforestry plantations, including food forests. All other tree plantations that do not qualify as Forest Land are included in the Grassland subcategory Trees outside Forest.

\section{Managed forest land and the Dutch forest inventory}

A distinction is still made worldwide between managed and unmanaged forests. In the Netherlands, however, we consider all forests to be managed. The Dutch forest inventories (NFI) are the most important source of information on the biomass and carbon stocks contained in Dutch forests.

\section{Reference level for carbon sequestration}

Under the EU LULUCF accounting rules, carbon sequestration in the managed forest land accounting category is compared with the reference level that would be expected to be achieved if no extra efforts are made to increase sequestration. This reference level is set down in the National Forestry Accounting Plan (NFAP) submitted by the Netherlands on 31 December 2019.

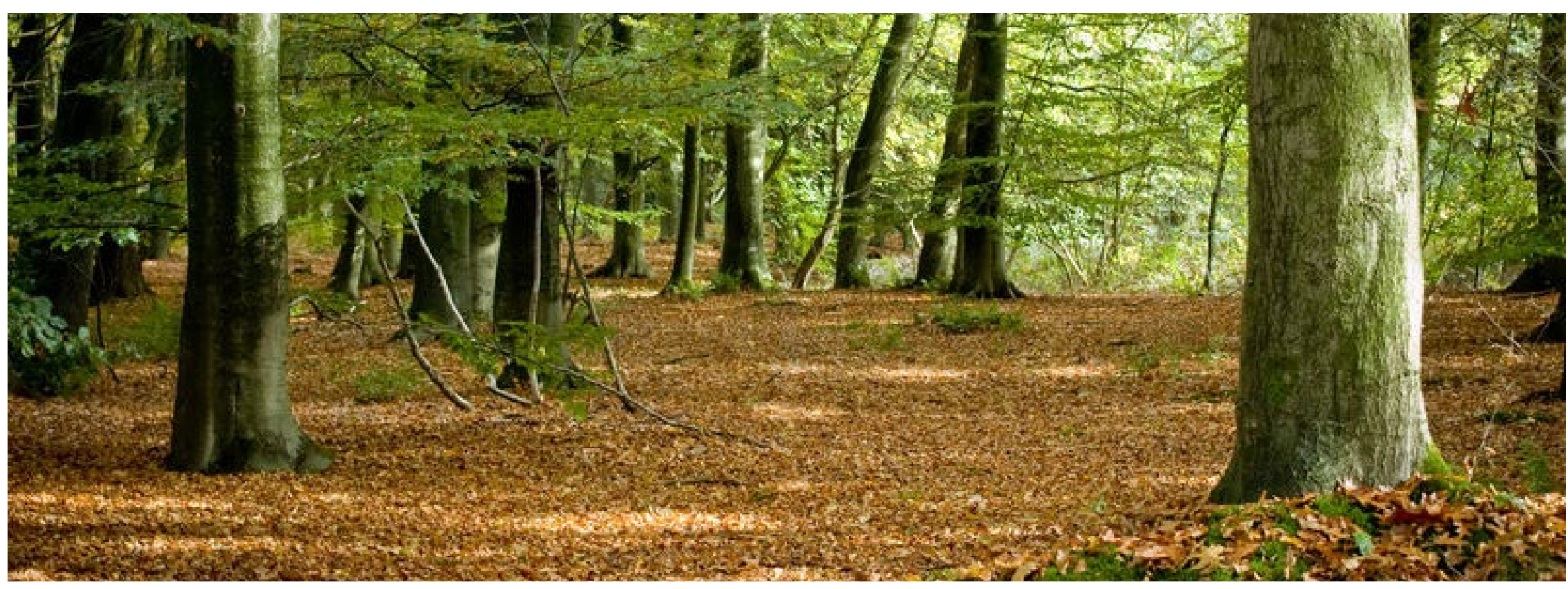

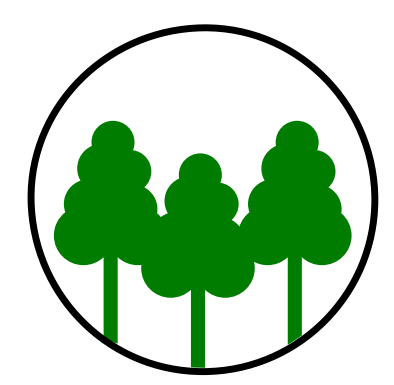

Forest Land

\section{Forest Land}

Forest Land remaining Forest Land

Land converted to

Forest Land

Methods \& Reporting

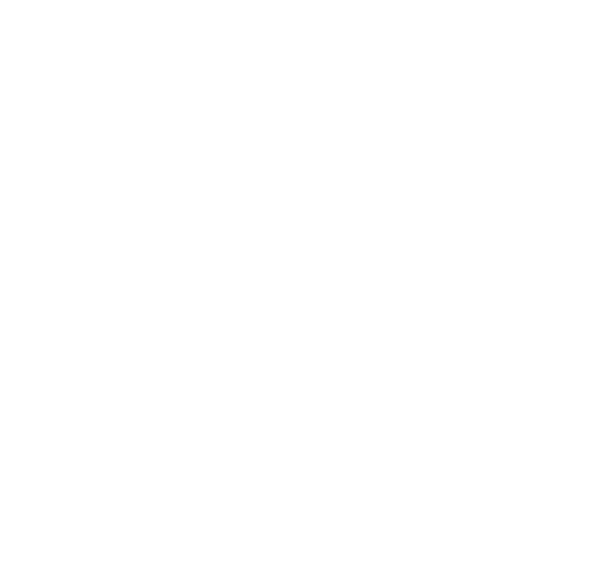




\section{Forest Land remaining Forest Land}

\section{Changes in carbon stocks}

The carbon balance for living biomass in Forest Land remaining Forest Land is based on data on growing stock and annual increment $s$ of wood from the Dutch national forest inventories (NFIs). Information on dead wood is also obtained from the NFIs.

NFI plot data are available from three inventories: the HOSP dataset (1988-1992) with 3,448 plots, the fifth National Forest Inventory (NFI-5, 2001-2005) with 3,622 plots and the sixth National Forest Inventory (NFI-6, 2012-2013) with 3,190 plots. The NFI-7 will be completed in 2021. Carbon storage in dead wood is also determined on the basis of measured values from these inventories combined with some general parameters. Carbon storage in the litter layer is estimated from information from the NFI- 5 and the NFI- 6 in combination with a number of additional national datasets on litter.

\section{Forest Land area and emissions}

The Dutch forest area is continually changing as a result of deforestation and new planting in other locations. Until 2013 the area of Forest Land in the Netherlands increased gradually from 362,000 ha in 1990 to 375,000 in 2013 (see Figure 6), with afforestation exceeding deforestation. Between 2013 and 2017, however, the net area of Forest Land decreased as a result of increased deforestation and delayed afforestation.

The decrease in the area of Forest Land after 2013 also meant a reduction in removals of $\mathrm{CO}_{2}$ compared with the previous years (see Figure 7).

\section{- Forest Land remaining Forest Land $\quad-$ to Forest Land - Forest Land total}

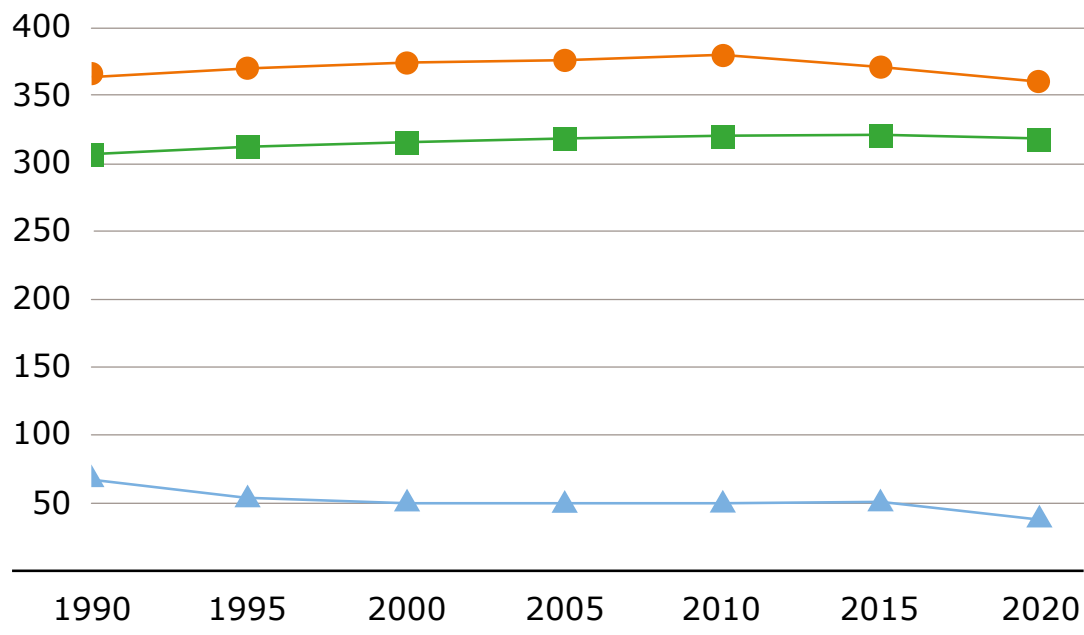

Figure 6: Trends in the area of Forest Land from 1990 to 2019. The period after 2017 is an extrapolation of the trend in the period 2013-2017. This will be updated when the new land use map is available.

Forest Land remaining Forest Land $\quad$ to Forest Land Forest Land total

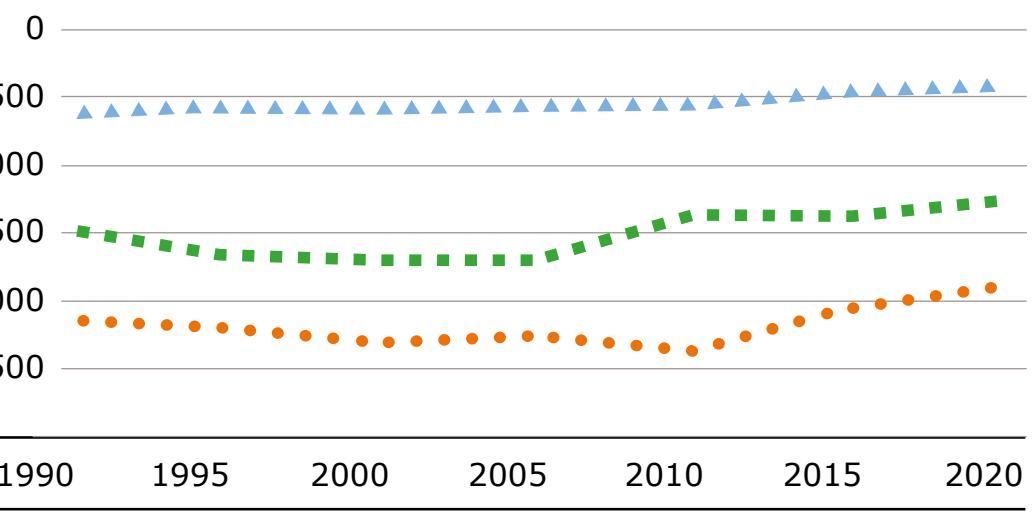

Figure 7: Time series for 1990-2019 of total $\mathrm{CO}_{2}$ emissions/removals in Forest Land remaining Forest Land and Land converted to Forest Land. Negative emissions mean that $\mathrm{CO}_{2}$ is removed from the atmosphere and the carbon is stored in biomass and/or the soil. Data from the NIR 2021.

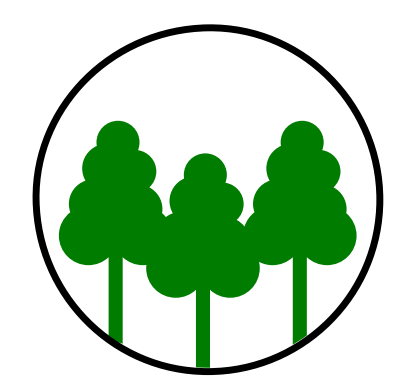

Forest Land

Forest Land

\section{Forest Land remaining} Forest Land

\section{Land converted to}

Forest Land

\section{Methods \& Reporting}

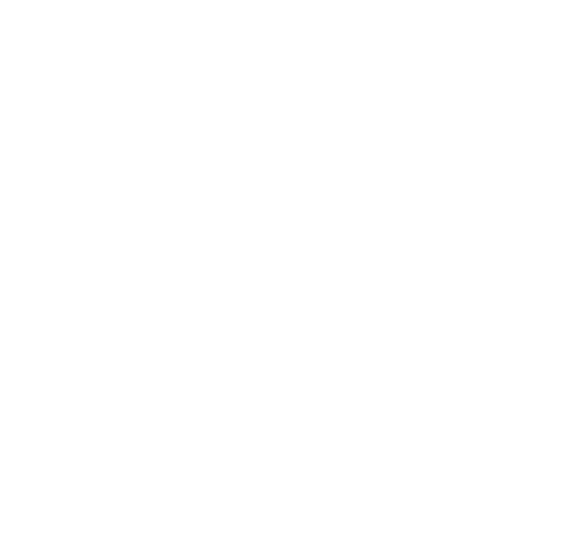




\section{Land converted to Forest Land}

\section{Changes in carbon stocks}

When other land uses are converted to Forest Land it is assumed that after an immediate loss of the original carbon stocks of Cropland and Grassland biomass in the year of conversion, carbon stocks in living above-ground and

below-ground biomass will gradually accumulate within 30 years to the levels that apply to Forest Land remaining Forest Land. This emission factor is indirectly derived from observations in the NFIs.

Because the rates of accumulation of carbon stocks in dead wood and litter are subject to considerable uncertainty and are probably relatively limited, they are not considered in the current system for the Netherlands. For the land-use change from Trees outside Forest it is assumed that the original tree cover does not change. The land retains the original carbon stock of Trees outside Forest, which from then on continues to increase at the same rate as for Forest Land remaining Forest Land.

\section{Deforestation}

Deforestation is not a separate category in the UNFCCC system. Emissions are reported under the subcategories
Forest Land converted to Cropland, Grassland, Wetlands, Settlements and Other Land. The method is always the same and is determined largely by the carbon stocks present in the Forest Land. The differences in carbon stocks in biomass and dead organic matter between the two land uses determines the emissions, with the loss of carbon from the original carbon pools, living biomass, dead wood and forest litter accounted for as an immediate emission.

Soil carbon stocks change gradually over the 20 year transition period, based on differences in soil carbon, as shown in Figure 4. The exception is Forest Land that is converted to Trees outside Forest. For this, it is assumed that the tree cover remains and that the above-ground and below-ground biomass remain the same. However, the loss of dead wood and litter is included in the emission calculation for this change of use.

On average, each hectare of deforestation (of mature forest) in the Netherlands results in emissions of about $0.5 \mathrm{kt} \mathrm{CO}_{2}$ due to the loss of carbon stocks in tree biomass and dead organic matter.

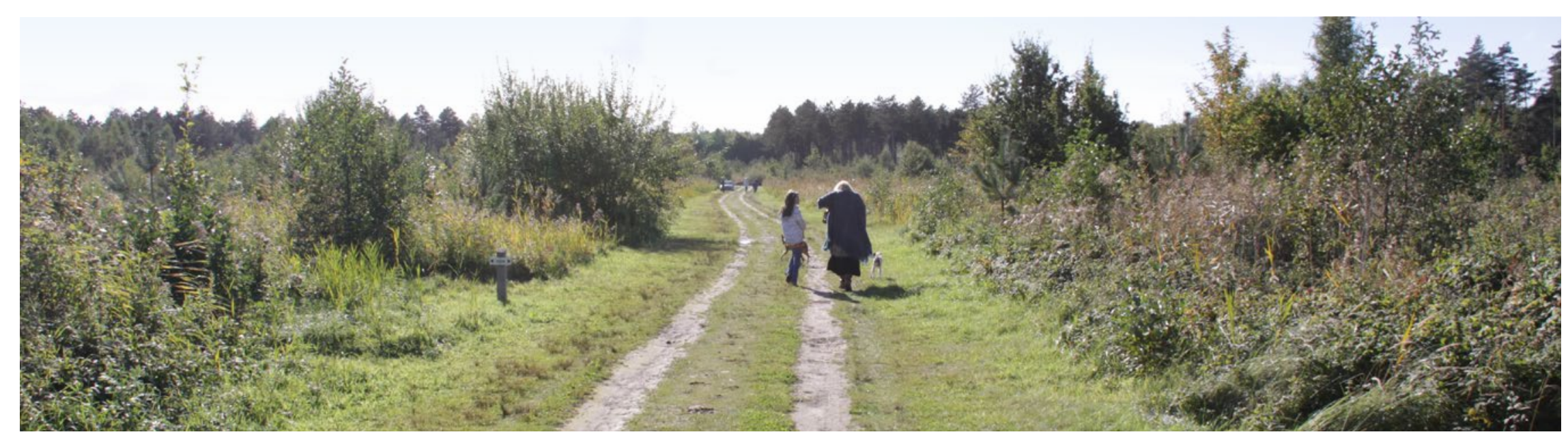

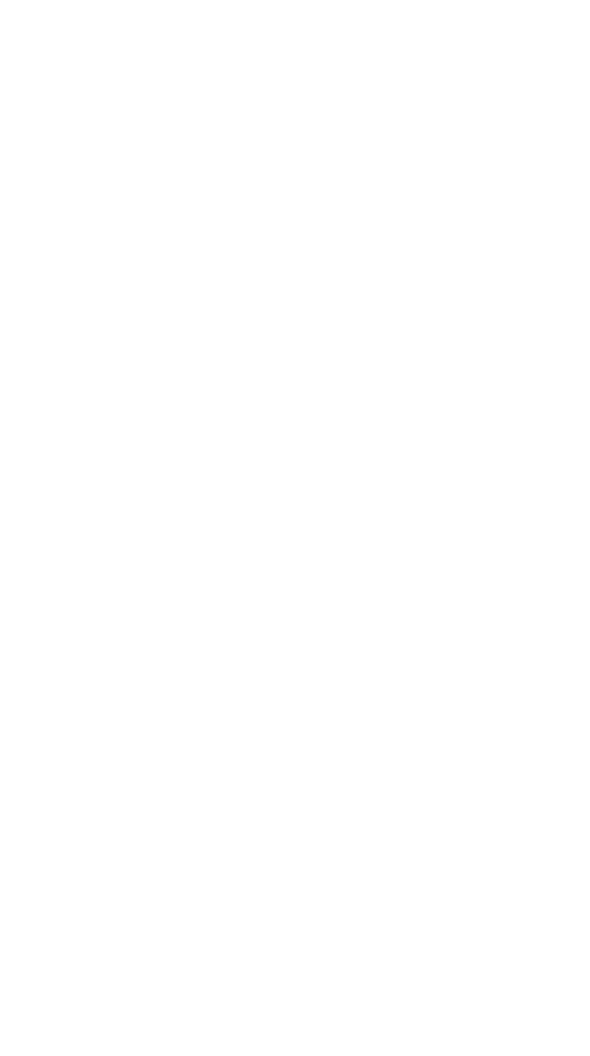

Forest Land remaining Forest Land

Land converted to Forest Land

Forest Land 


\section{Cropland}

\section{Definition of land use category Cropland}

Cropland is defined by the IPCC as arable land and agroforestry systems that do not fall within the Forest Land category. The Netherlands has chosen to include all arable land and tree nurseries in this category, because this best reflects the Dutch situation and IPCC rules. Alternating crops and grassland in a crop rotation cannot be recorded as a separate category in the current LULUCF system and the effects are taken into consideration only if the land-use changes in the period between the two maps. Based on the land use map, the land is classified as either Cropland or Grassland. These categories do not include greenhouse horticulture, which is included in Settlements.

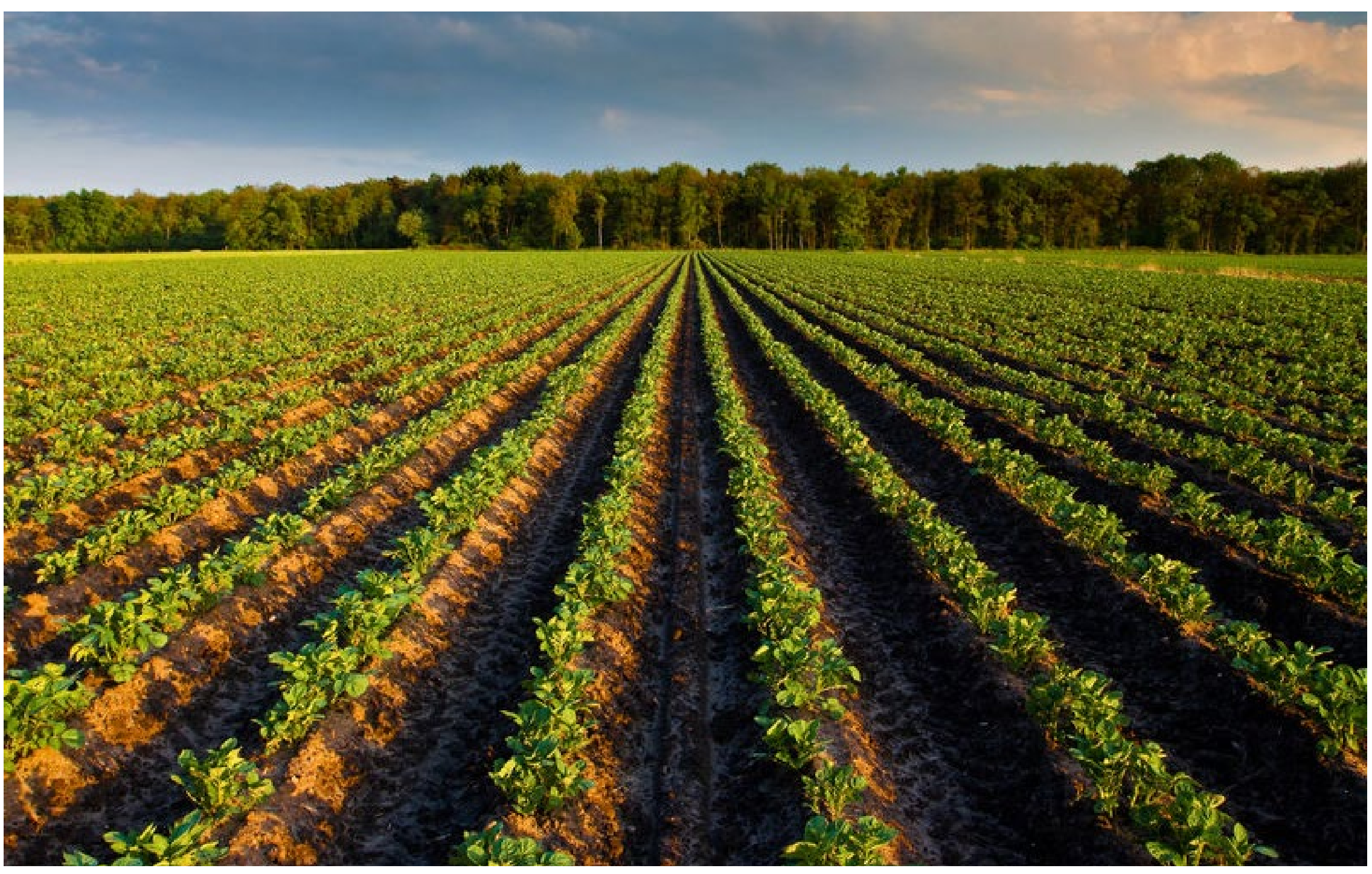

Cropland

\section{Cropland}

\section{Cropland remaining} Cropland

Land converted to

Cropland

\section{Methods \& Reporting}

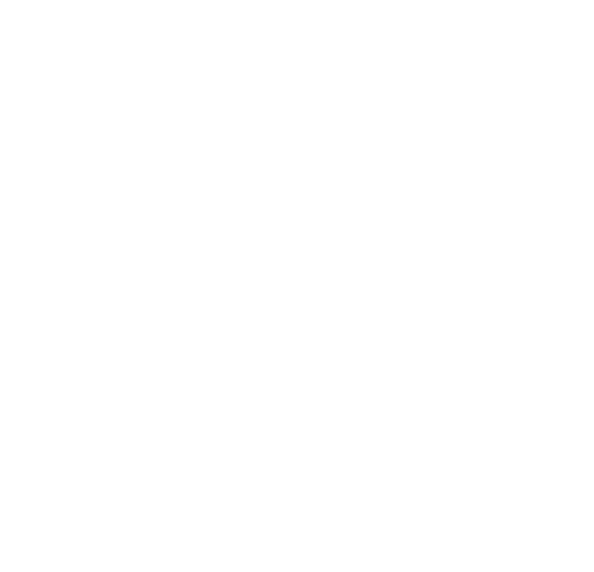




\section{Cropland remaining Cropland}

\section{Changes in carbon stocks}

We assume that biomass does not accumulate in arable land. The annual increase in biomass is assumed to be equal to the annual decrease due to harvesting, with the exception of woody perennial crops. In Dutch agriculture, woody perennial crops are mostly fruit orchards, but they are included in the Grassland category because the soil cover consists mostly of grass. Changes in soil carbon in orchards are therefore determined in the same way as for Grassland.

In the Netherlands, arable land is dominated by annual crops that are harvested at the end of the growing season. For this reason, the Netherlands does not record any changes in living biomass and biomass stocks within the Cropland remaining Cropland category.

\section{Emissions from organic soils}

Emissions from peat soils and peaty soils under agricultural use are the main source of emissions within the Cropland and Grassland categories and are also the main source of emissions in the entire LULUCF sector. These emissions are from the oxidation of organic matter caused by lowering the groundwater level to facilitate certain agricultural activities, particularly dairy farming. This results in soil subsidence and an estimated emission of $5.6 \mathrm{CO}_{2}$ eq. Most of the emissions (4.1 $\mathrm{Mt} \mathrm{CO}_{2}$ ) are from drained peat meadows in the West and North of the country.
Cropland

Cropland

\section{Cropland remaining}

\section{Cropland}

Land converted to

Cropland

Methods \& Reporting
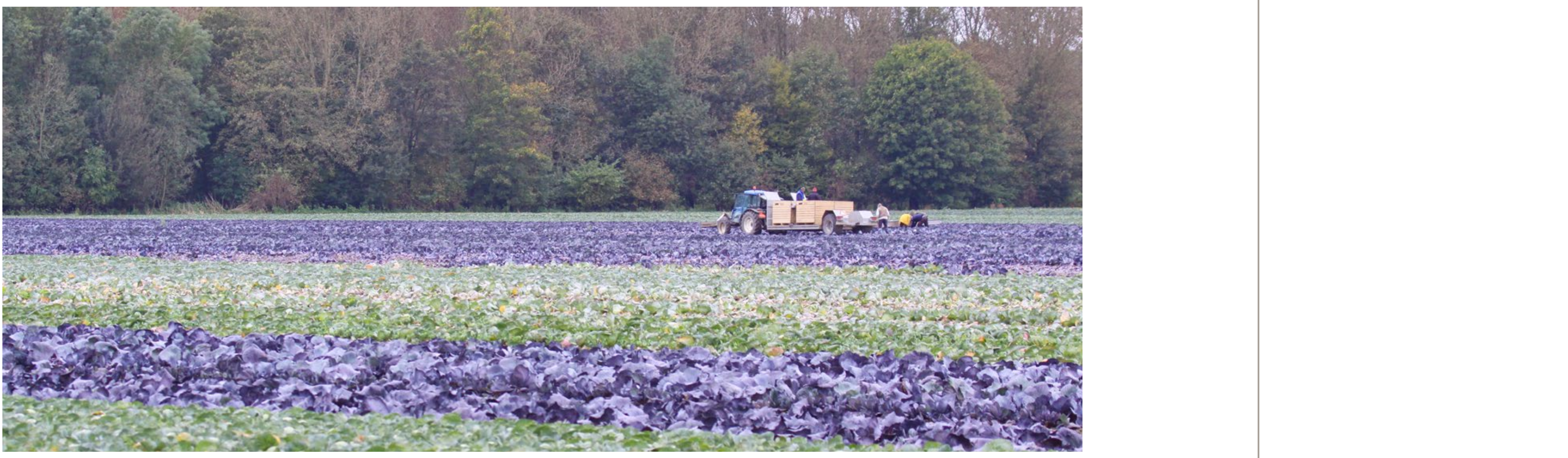


\section{Cropland area and emissions}

The Cropland area is gradually decreasing over time (see Figure 8). In the period since 2013 this has been mainly due to changing EU regulations on temporary and permanent grassland which have led to relatively more cropland being converted to grassland than vice versa. Emissions from Cropland are also gradually decreasing over time (see Figure 9), the main reason being that emissions from drained peat soils are decreasing. At the moment (2021) this is not a direct consequence of measures included in the National Climate Agreement, but the result of the declining area of peatland. Due to continuous drainage the peat oxidises and is lost to the atmosphere in the form of $\mathrm{CO}_{2}$. Eventually the peat will all disappear and these emissions will cease.

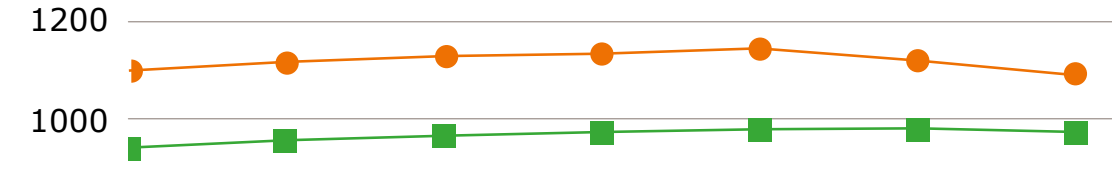

800 600

400

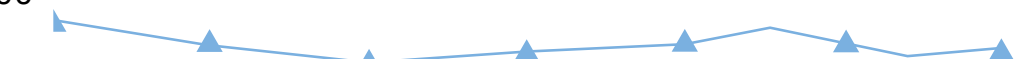
200

\begin{tabular}{lllllll}
\hline 1990 & 1995 & 2000 & 2005 & 2010 & 2015 & 2020
\end{tabular}

Figure 8: Trends in the area of Cropland from 1990 to 2019. The period after 2017 is an extrapolation of the trend in the period 2013-2017. This will be updated when the new land use map is available.

- Cropland remaining Cropland $\Delta$ to Cropland Cropland total 3000

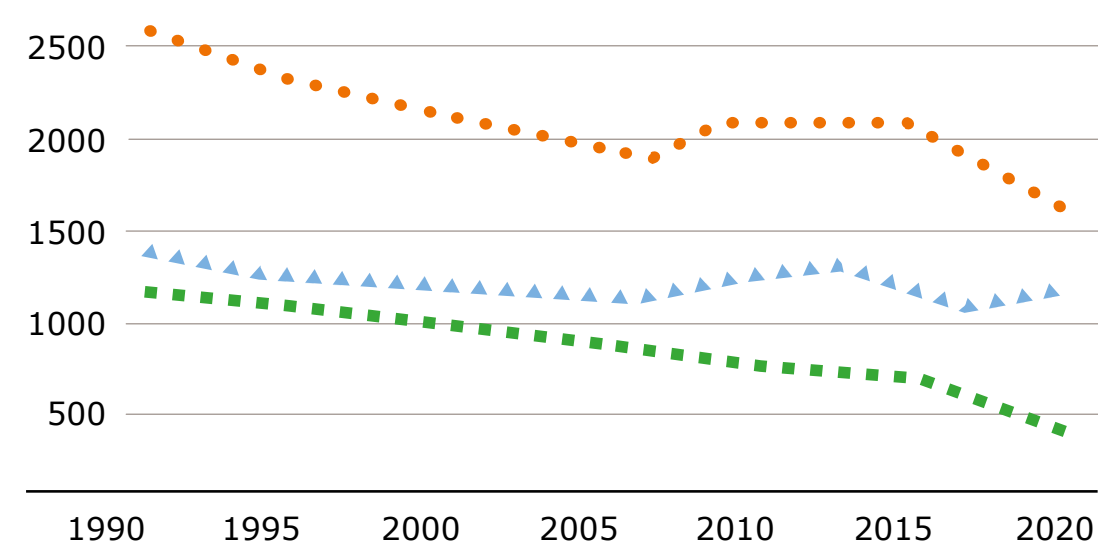

Figure 9: Time series for 1990-2019 of total $\mathrm{CO}_{2}$ emissions/removals in Cropland remaining Cropland and Land converted to Cropland. Data from Cropland remaini
the NIR 2021.

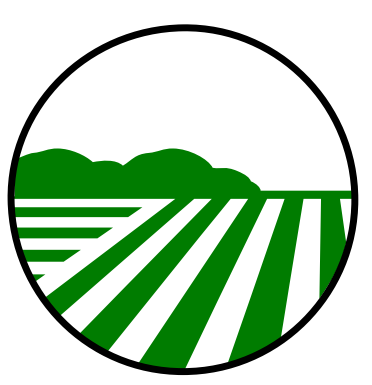

Cropland

Cropland

\section{Cropland remaining} Cropland

\section{Land converted to Cropland}

\section{Methods \& Reporting}

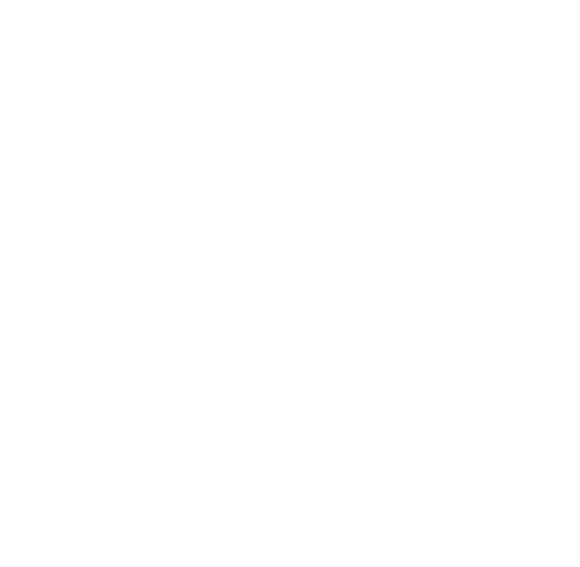




\section{Land converted to Cropland}

\section{Changes in carbon stocks}

For Land converted to Cropland we calculate a change in the carbon stock according to the simple Tier 1 method, using a single standard value ( $5 \mathrm{t} \mathrm{C/ha)}$ and assuming that the aboveground and below-ground biomass are the same.
Changes in soil carbon stock are determined on the basis of soil type (see Figure 4). Each soil type has a specific change in carbon stock when land is converted to Cropland. The annual emissions and removals over the 20 years that Land converted to Cropland is reported in this category are calculated as $1 / 20$ of the difference in carbon stocks between the original land use and the new land use.

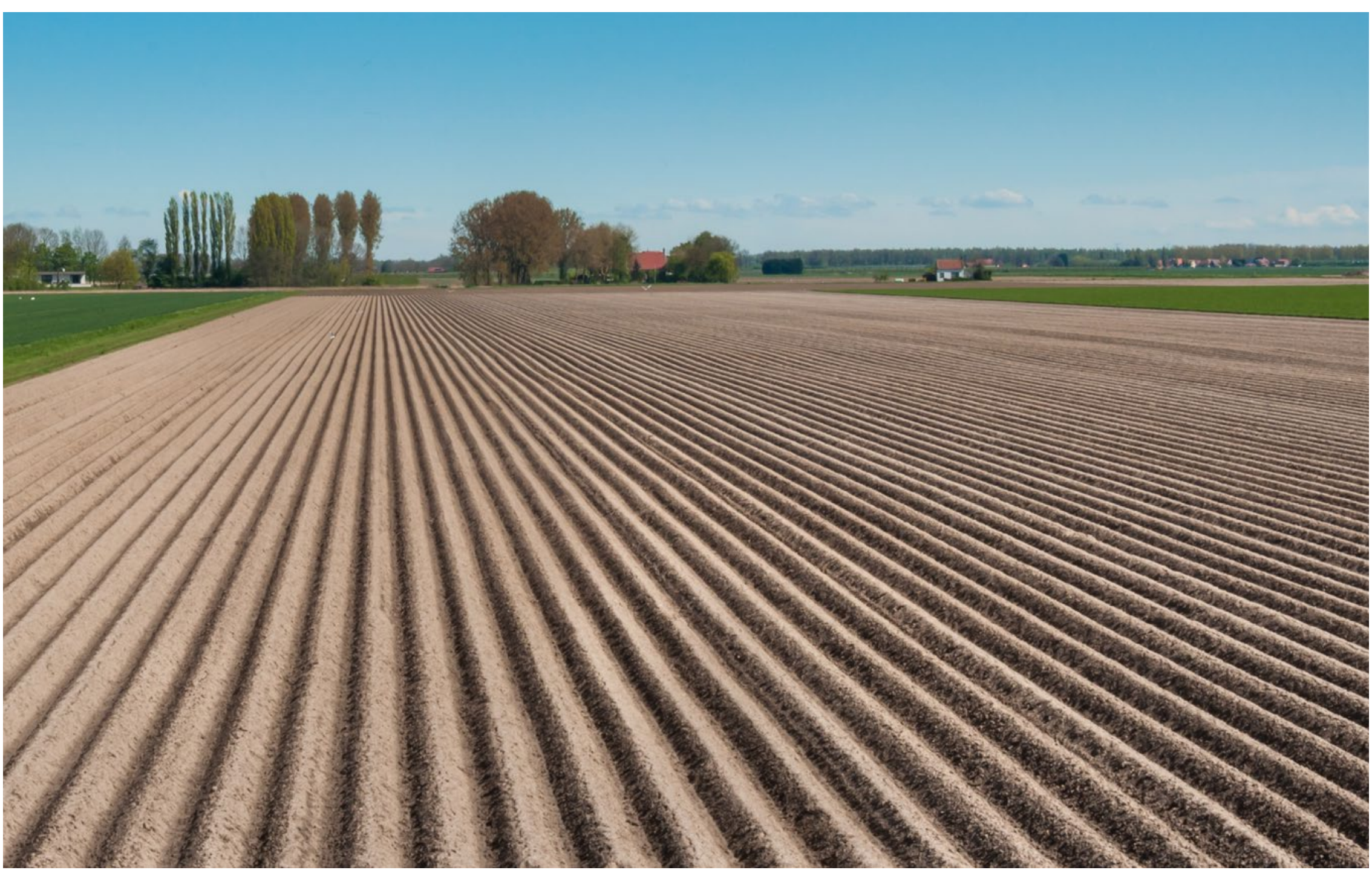

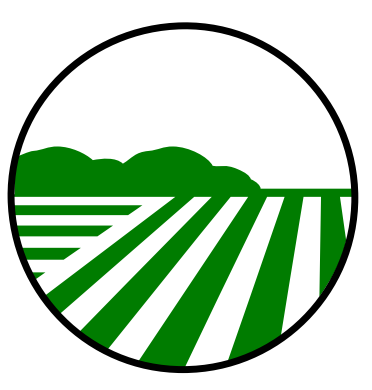

Cropland

Cropland

Cropland remaining Cropland

\section{Land converted to Cropland}

Methods \& Reporting

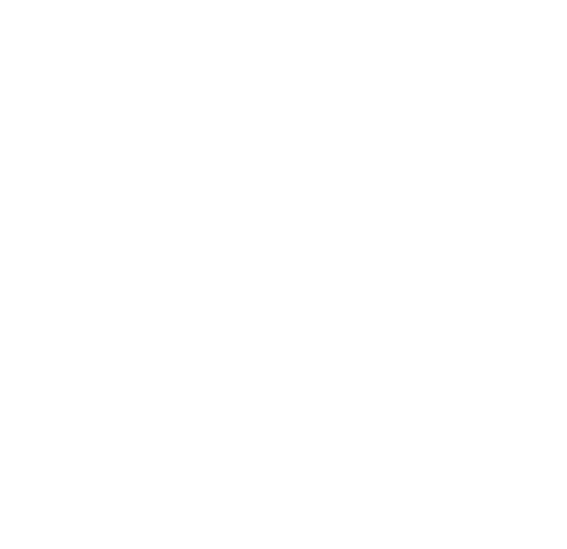




\section{Grassland}

\section{Definition of land use category Grassland}

Grassland is divided into two subcategories: Grassland and Trees outside Forest. The first category includes all areas (cultivated, recreational or natural) dominated by grassland vegetation, nature with grassland vegetation, and fruit orchards. Fruit orchards are included in this category because in the Netherlands grass is the predominant soil cover under the fruit trees. In the methodologies no difference is made between intensive and extensive grassland management.

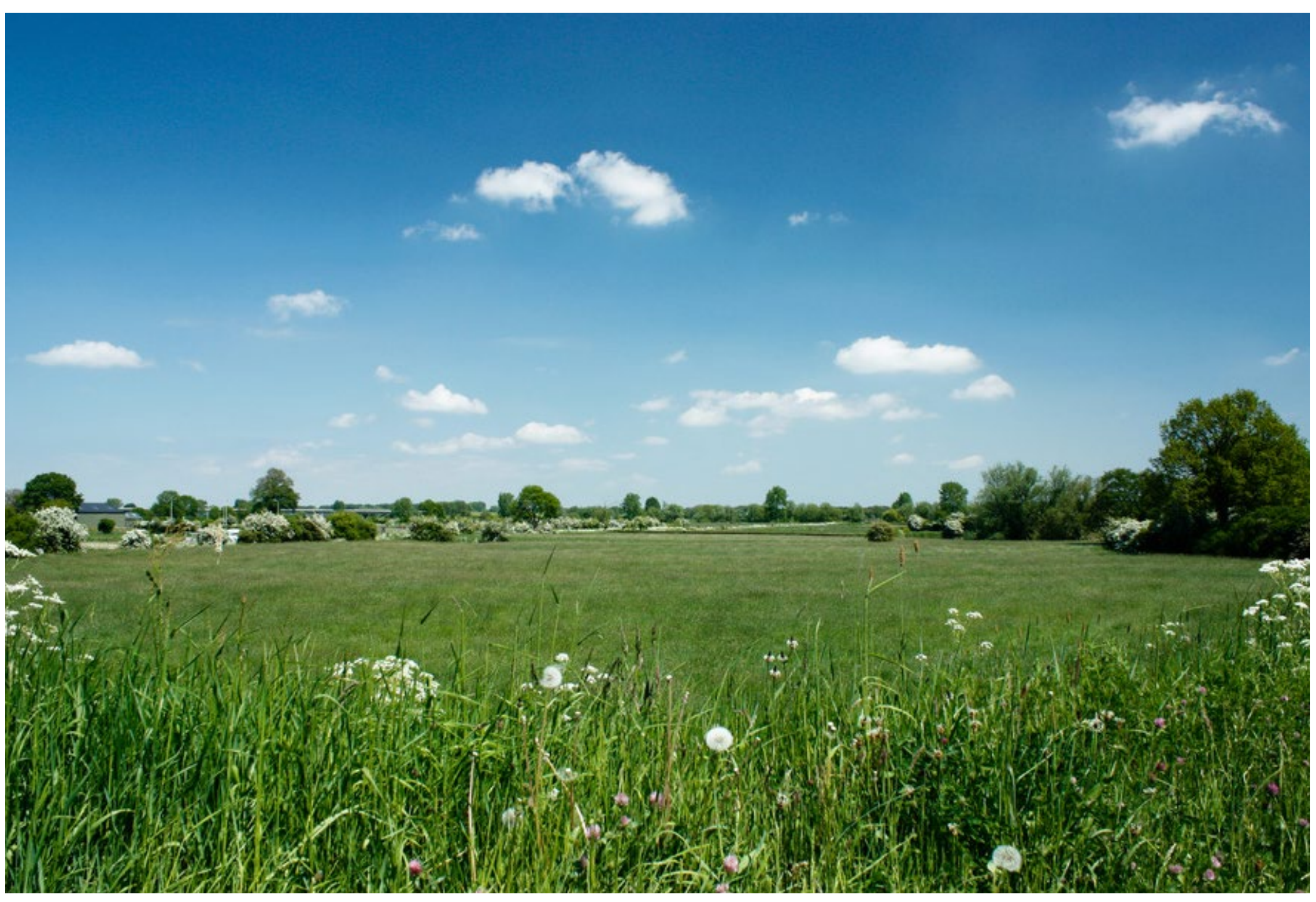

Grassland

\section{Grassland}

Grassland remaining Grassland

Land converted to

Grassland

Methods \& Reporting

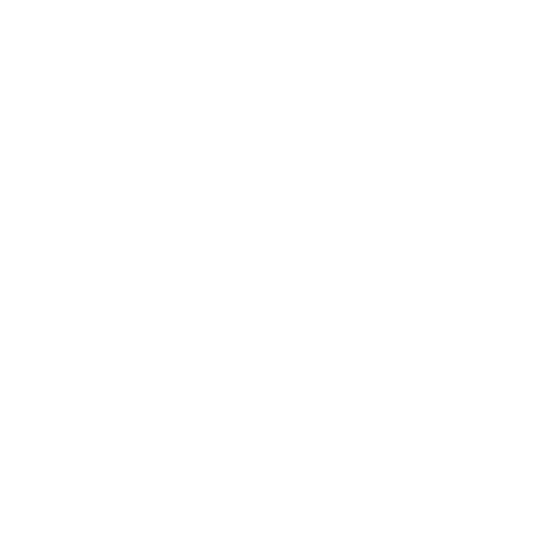




\section{Grassland remaining Grassland}

\section{Changes in carbon stocks}

According to the IPCC Tier 1 methodology, changes in biomass in Grassland are considered to be limited, because growth and death of biomass are in balance. Nevertheless, the dead biomass is a carbon input to the soil and as a result Grasslands usually have a high soil carbon stock. For the Netherlands, we also assume that changes in the carbon stock in living biomass in Grassland does not change over a period of one year. The carbon stock in orchard biomass is based on the average age of the trees (10.5 years) and a biomass accumulation of $2.1 \mathrm{t}$ $\mathrm{C} / \mathrm{ha} /$ year (IPCC, 2003) and is therefore $22 \mathrm{t} \mathrm{C/ha.} \mathrm{Changes} \mathrm{in}$ the carbon stock arise only from changes in land use.

\section{Trees outside Forest}

Due to a lack of data we assume that trees in the Trees

outside Forest category grow in the same way as trees in the
Forest Land category. Individual areas in the Trees outside Forest category must be smaller than 0.5 ha, otherwise they fall within the Forest Land category. For the Trees outside Forest category it is also assumed that there is no accumulation of dead organic material and that these do not contribute to harvested wood.

As soon as Grassland is converted to Trees outside Forest or vice versa the resulting carbon stock changes in biomass are considered, even though both fall within the Grassland category and the resulting carbon stock changes and emissions are reported under Grassland remaining Grassland. In the year of conversion Grassland converted to Trees outside Forest will lose the carbon stocks in grassland biomass, but at the same time will gain carbon stocks in the Trees outside Forest biomass. The same applies the other way around.
Grassland

Grassland

Grassland remaining Grassland

\section{Land converted to}

Grassland

Methods \& Reporting
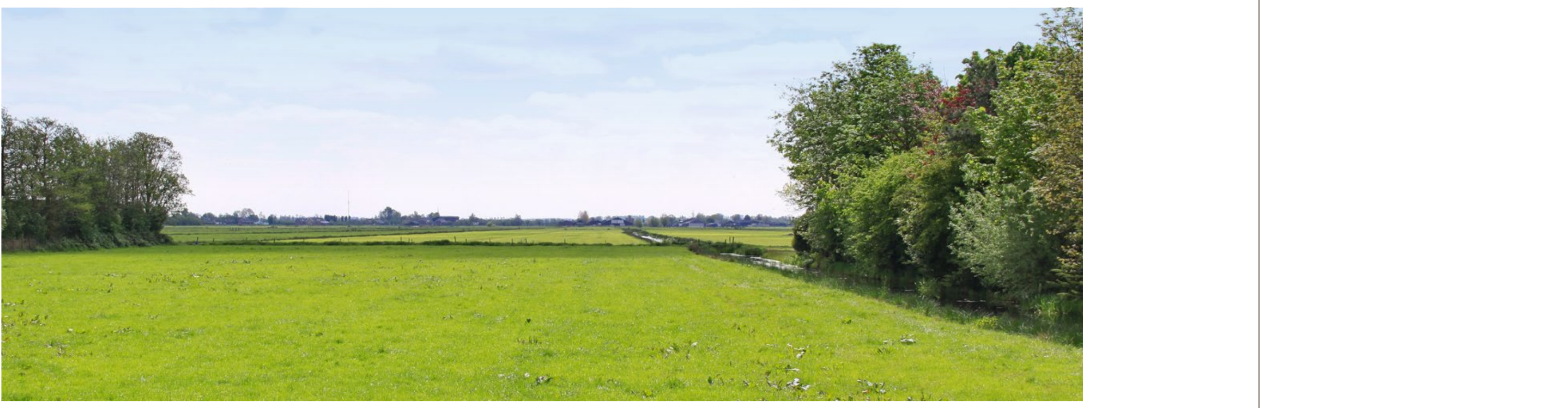


\section{Grassland area and emissions}

As with Cropland, emissions from peat soils and peaty soils are significant contributors to Grassland emissions and to the LULUCF sector as a whole.

The total Grassland area remained more or less the same during the period 1990-2019, but the area of Grassland remaining Grassland continues to decrease gradually and the area of Land converted to Grassland is increasing (see Figure 10). This is the result of the relatively high rate of conversion between Grassland and Cropland. In recent years there has been more conversion from Cropland to Grassland than vice versa.

Emissions from Grassland are gradually decreasing over time (see Figure 11), the main reason being that emissions from drained peat soils are decreasing. At the moment (2021)

this is not a direct consequence of measures included in the National Climate Agreement, but the result of the declining area of peatland. Continuous drainage leads to oxidation of the peat, resulting in $\mathrm{CO}_{2}$ emissions and reductions in the volume of peat. Eventually, the peat will all disappear and these emissions will cease.

\section{Grassland}

\section{0}

1600

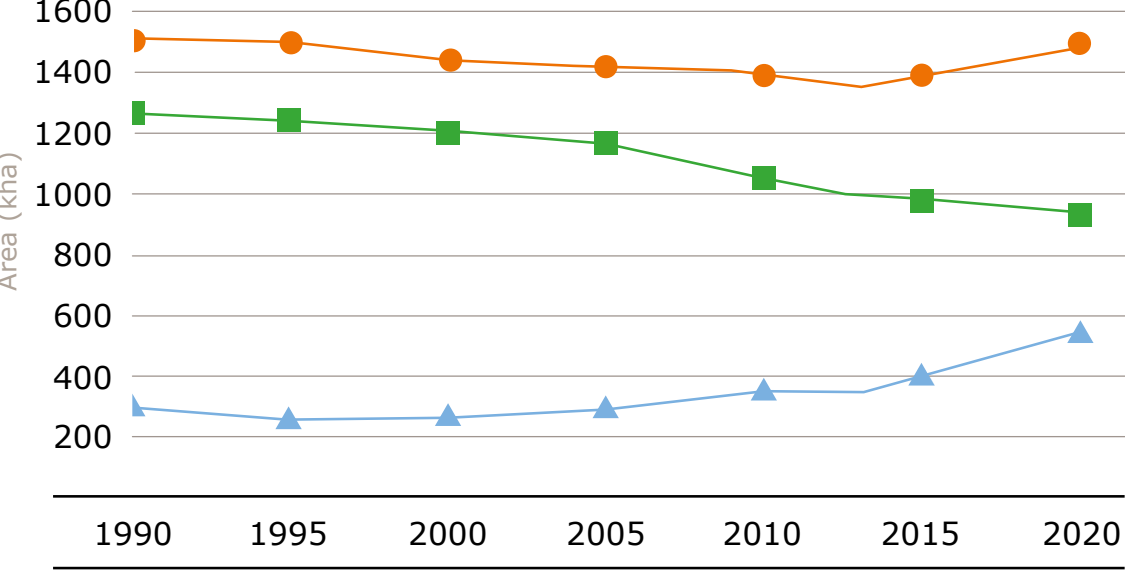

Figure 10: Trends in the area of Grassland from 1990 to 2019. The period after 2017 is an extrapolation of the trend in the period 2013-2017. This will be updated when the new land use map is available.

Grassland remaining Grassland $\Delta$ to Grassland Grassland total

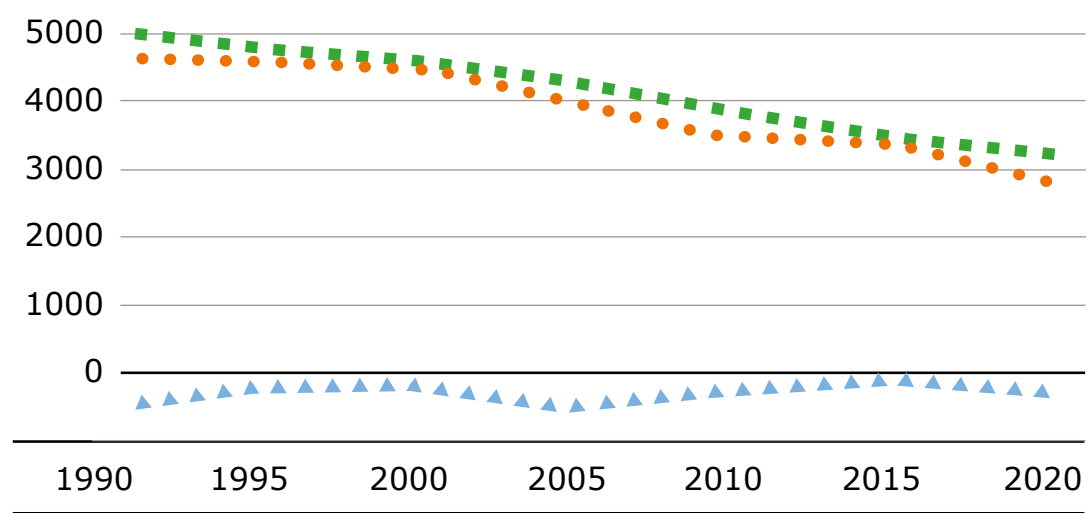

Figure 11: Time series for 1990-2019 of total $\mathrm{CO}_{2}$ emissions/removals in Grassland remaining Grassland and Land converted to Grassland. Negative emissions mean that $\mathrm{CO}_{2}$ is removed from the atmosphere and the carbon is stored in biomass and/or the soil. Data from the NIR 2021.
Grassland

\section{Grassland remaining} Grassland

\section{Land converted to Grassland}

\section{Methods \& Reporting}

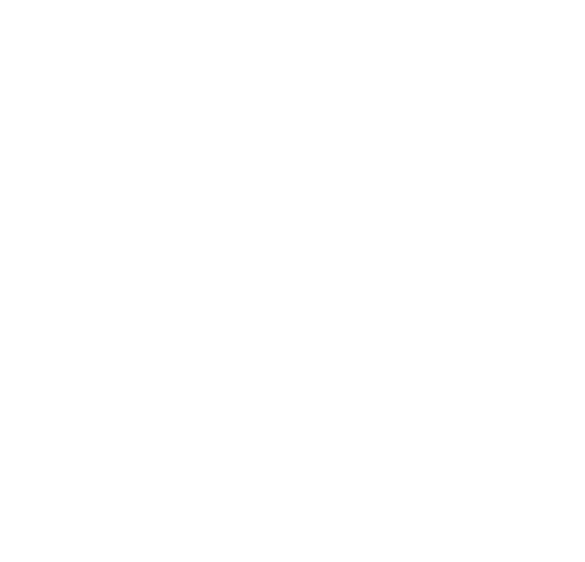




\section{Land converted to Grassland}

\section{Changes in carbon stocks}

Changes in the carbon stocks of Grassland arise only from changes in land use. Land converted to Grassland (or nature) is recorded as such for the first 20 years. Thereafter it is included in the Grassland remaining Grassland category. $\mathrm{CO}_{2}$ emissions due to changes in the carbon stock of living biomass are calculated using a simple Tier 1 method that depends on the area within the Grassland category. This method assumes a carbon stock of $13.6 \mathrm{t} \mathrm{C/ha}$ in Grassland and four times as much above-ground biomass than below-ground biomass. Changes in the soil carbon stock in Land converted to Grassland depend on the soil type (see Figure 4).
The annual emissions and removals over the 20 years that Land converted to Grassland has been reported in this category are calculated as $1 / 20$ of the difference in carbon stocks between the original land use and the new land use.

If the land-use changes from Forest Land to Trees outside Forest, the amount of carbon in dead plant material will decrease. In the Netherlands Land converted to Grassland on balance removes $\mathrm{CO}_{2}$ from the atmosphere (see Figure 11).

This is the result of the net sequestration of carbon in grassland soils, which is particularly high when arable land is converted to grassland.

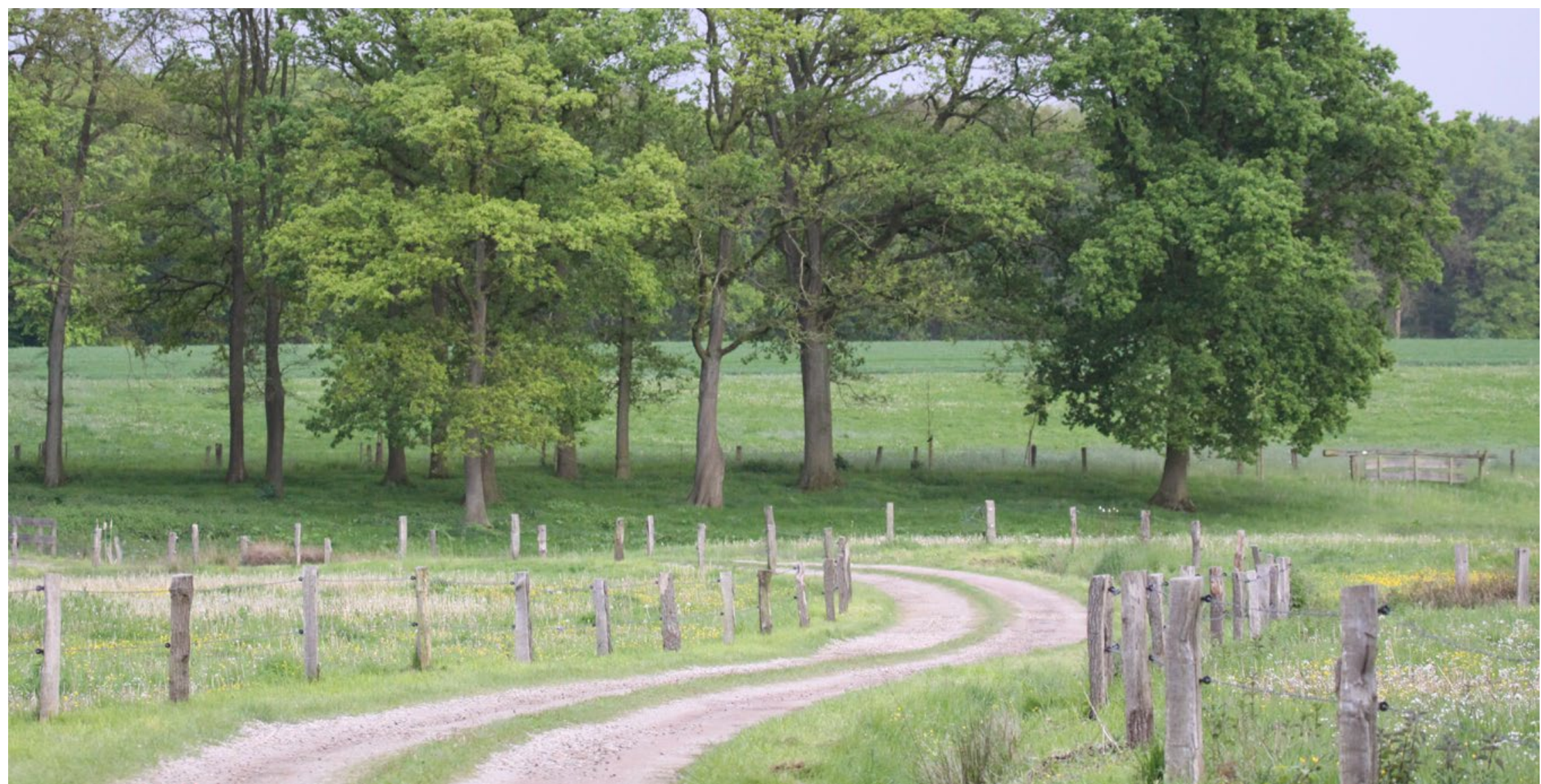

Grassland

Grassland

Grassland remaining Grassland

\section{Land converted to Grassland}

\section{Methods \& Reporting}

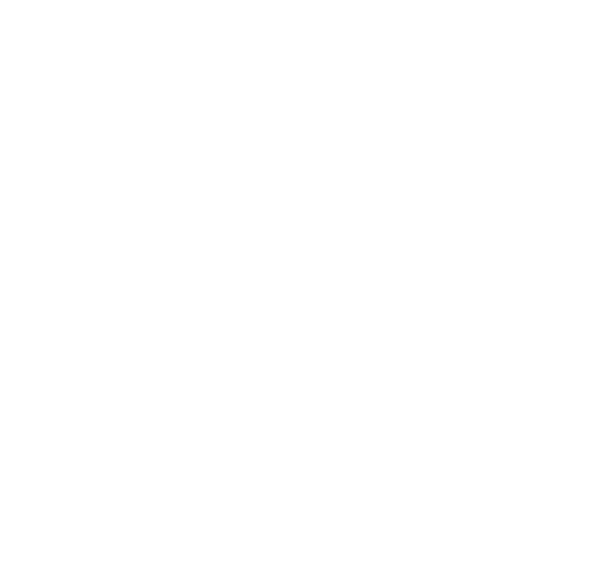




\section{Wetlands}

Definition of land use category Wetlands

In the Netherlands LULUCF reporting, the Wetlands

category consists mainly of open water such as lakes, rivers,

the coastal inlets in the Zeeland estuary, the IJsselmeer lake

and the Wadden Sea, as well as the areas of former peat

extraction with open water and reed marshes. Wet areas covered with grassland or forest are not included in the Wetlands category. In the Netherlands, therefore, only reed marshes and open water (e.g. ditches and lakes) and areas without vegetation that are temporarily flooded (e.g. by tides) fall within this category.

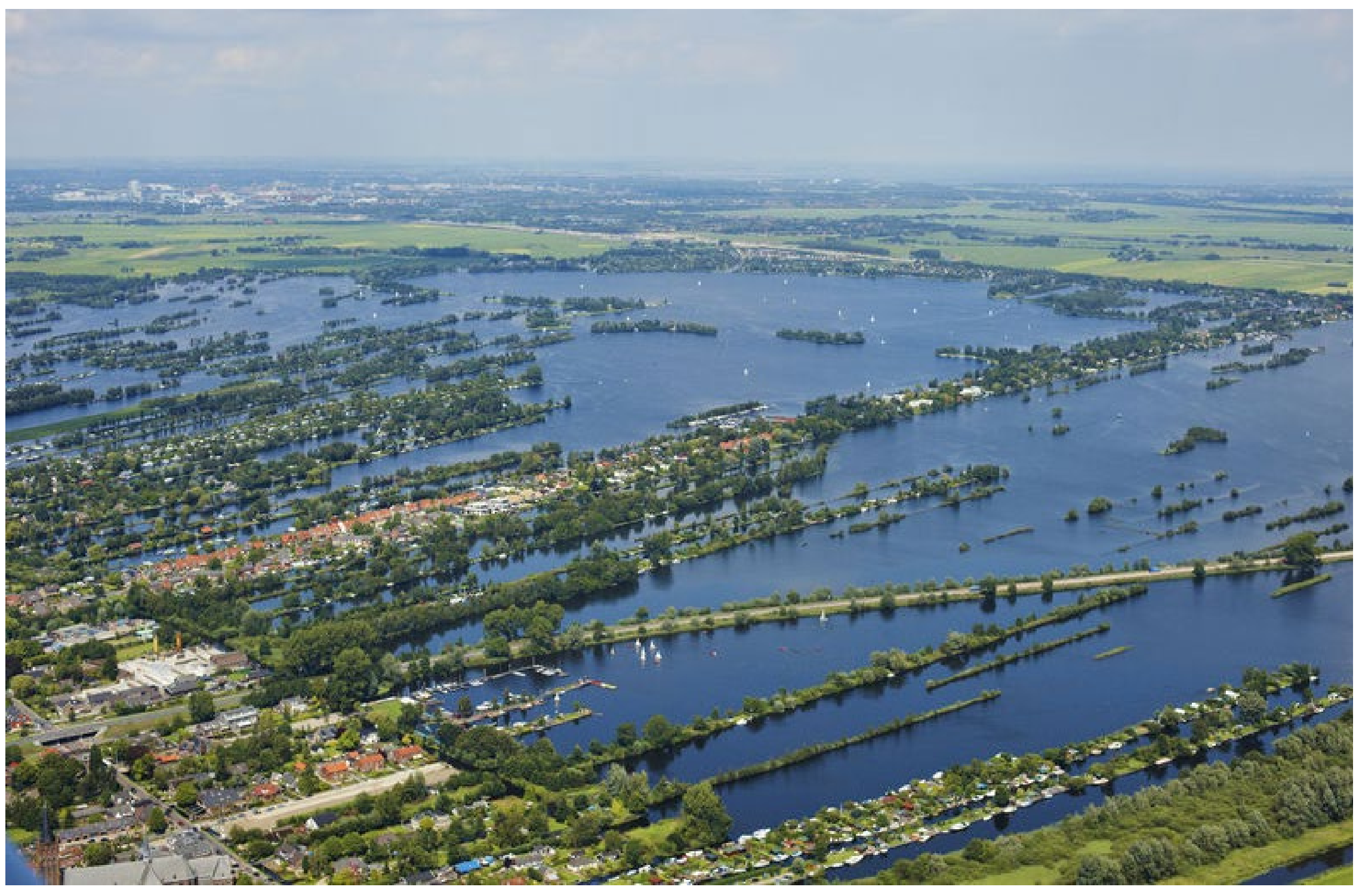

Wetlands

\section{Wetlands}

Wetlands remaining Wetlands

Land converted to

Wetlands

Methods \& Reporting

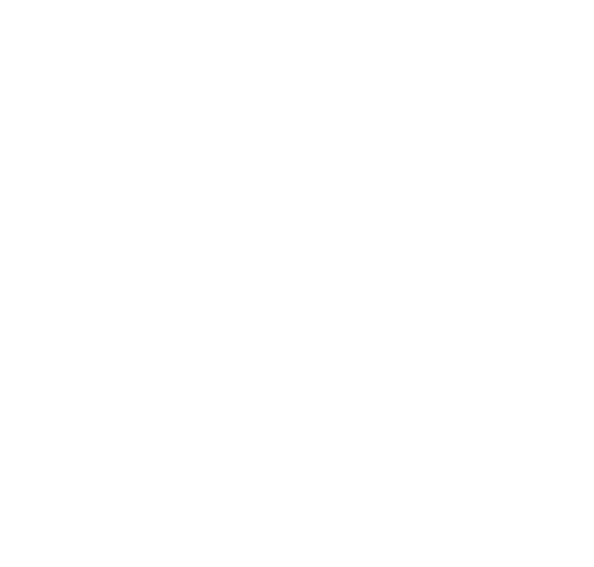




\section{Wetlands remaining Wetlands}

As described in the IPCC guidelines, for the Netherlands it is assumed that there are no emissions from Wetlands. This is currently under revision, because there are indications that emissions do occur. The area and emissions for Wetlands are shown in Figure 12 and 13.

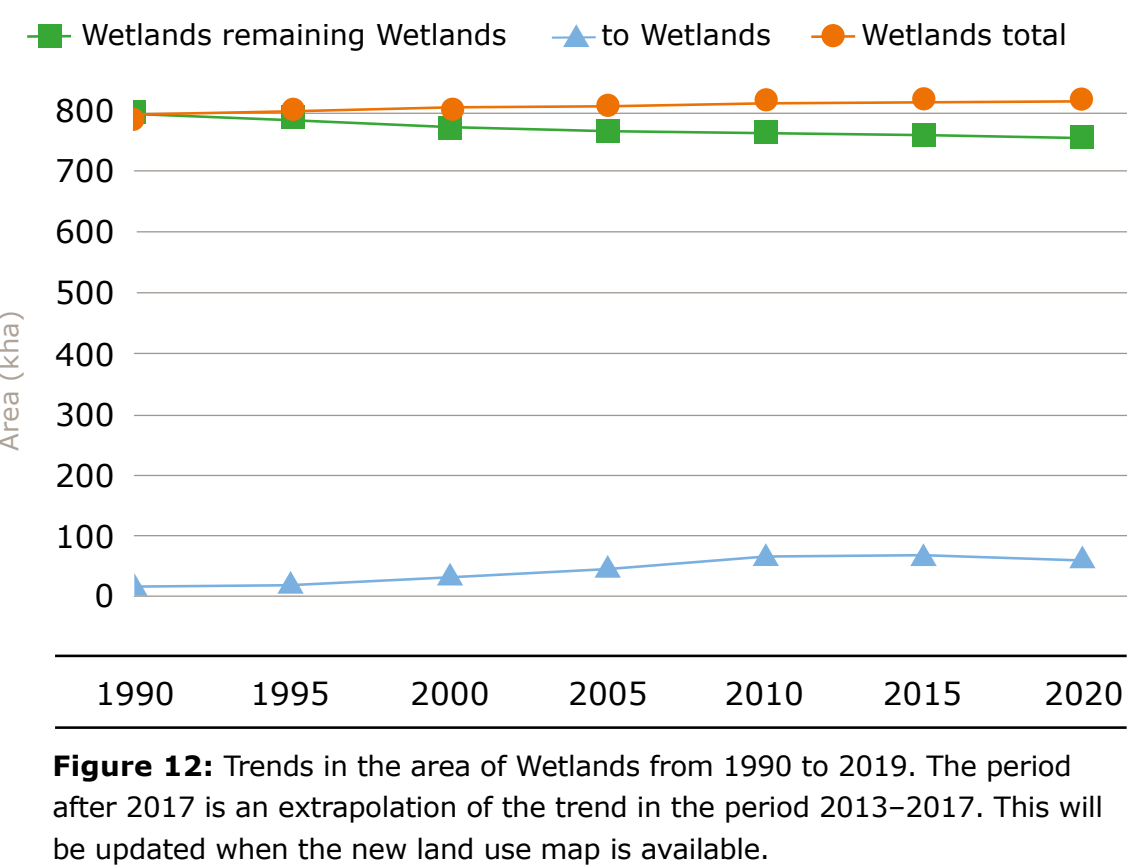

Wetlands remaining Wetlands $\Delta$ to Wetlands Wetlands total

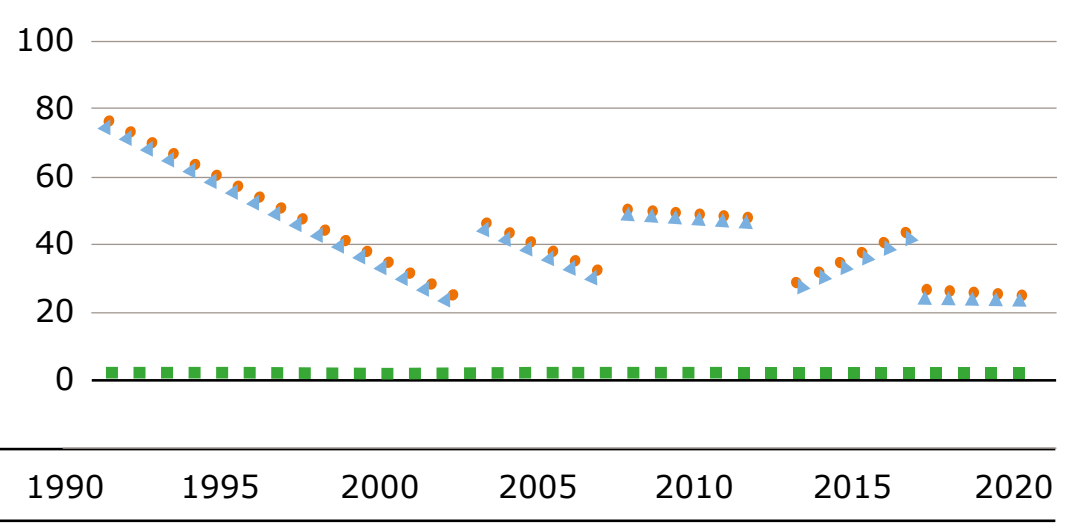

Figure 13: Time series for 1990-2019 of total $\mathrm{CO}_{2}$ emissions/removals in Wetlands remaining Wetlands and Land converted to Wetlands. Data from the NIR 2021.
Wetlands

Wetlands

\section{Wetlands remaining} Wetlands

\section{Land converted to}

Wetlands

\section{Methods \& Reporting}

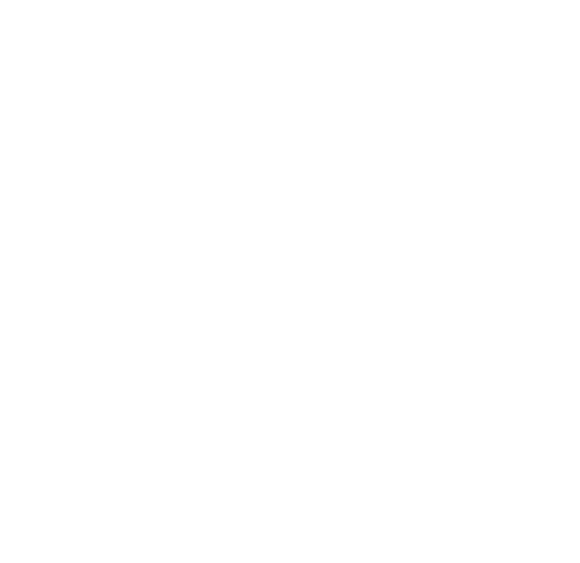




\section{Land converted to Wetlands}

\section{Changes in carbon stocks}

Carbon stocks in Wetlands are considered to be zero. When land is converted to Wetlands we therefore assume that all organic matter that was previously present is lost in the form of atmospheric emissions. This assumption is in line with the IPCC guidelines. Converting Forest Land or Grassland to Wetlands will therefore result in a decrease in the stock of biomass. It is also assumed that there are no changes in soil carbon stock. This is currently under revision, because there are indications that changes do occur.

\section{Wetlands}

\section{Wetlands}

Wetlands remaining Wetlands

\section{Land converted to Wetlands}

Methods \& Reporting

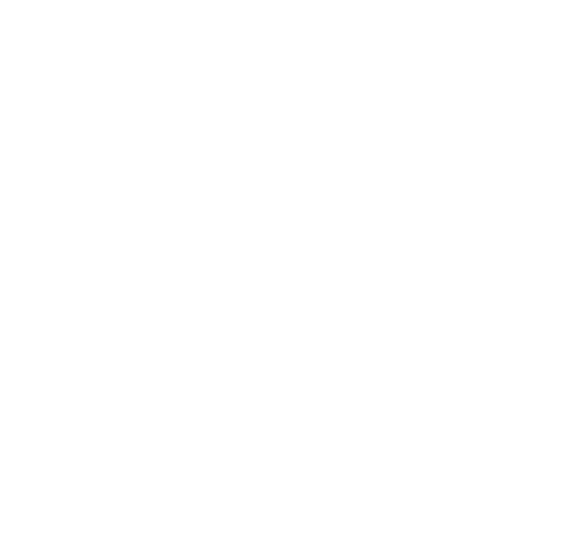




\section{Settlements}

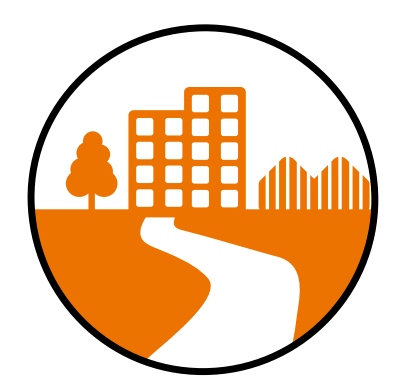

\section{Definition of land use category Settlements}

Settlements includes all human-made structures and

transport infrastructure (e.g. roads and railways). All

permanent structures built on the land surface used for

residence, trade, transport or labour are included in this category, regardless of the construction materials used.

This means that petrol stations, car parks, cemeteries and

greenhouses also belong in this category, as do paved and unpaved roads more than six metres wide.

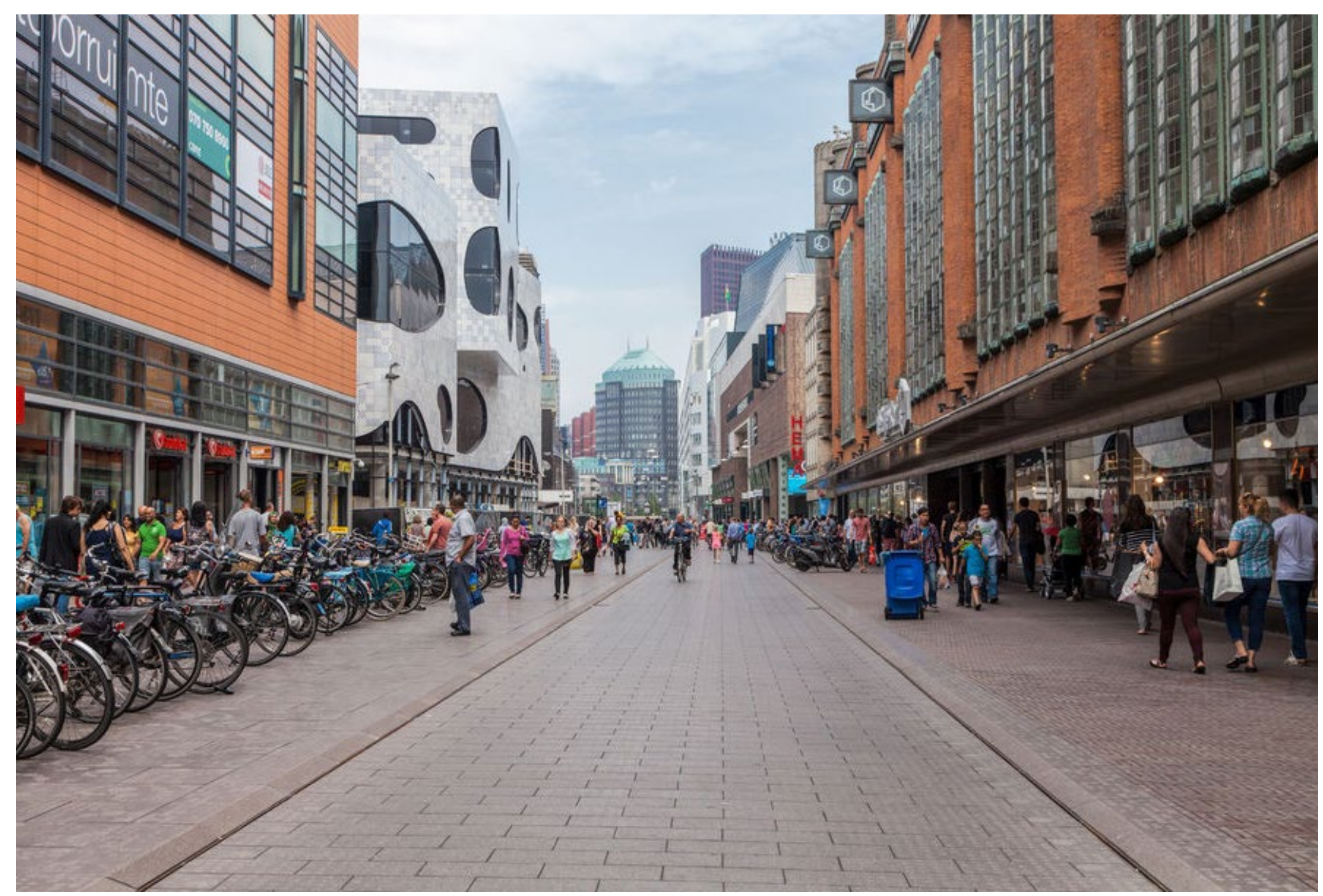

\section{Settlements}

Settlements remaining Settlements

Land converted to

Settlements

Methods \& Reporting

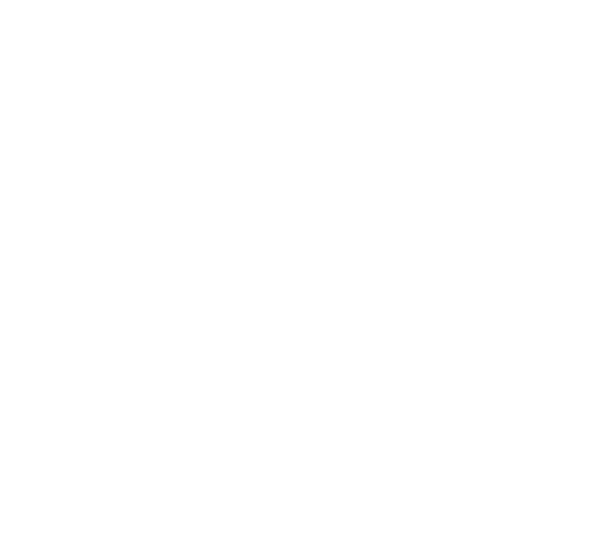




\section{Settlements remaining Settlements}

Although grass and trees may be found in this category (but do not meet the definition), the task force assumes that there is no change in biomass in this category. The area and emissions for Settlements are shown in Figure 14 and 15.
- Settlements remaining Settlements - to Settlements - Settlements total

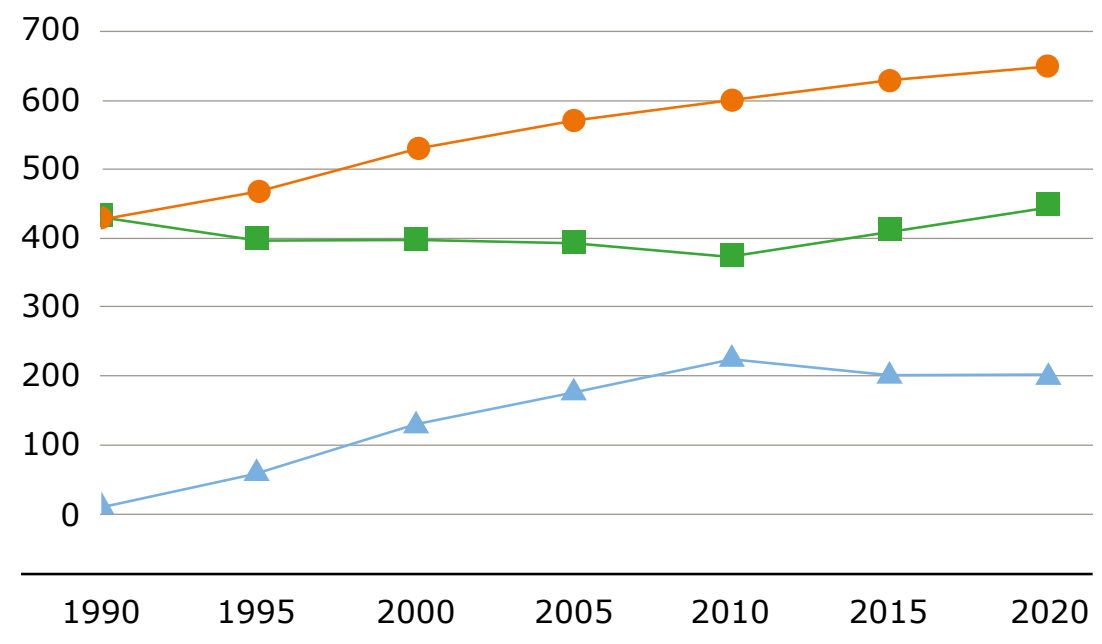

Figure 14: Trends in the area of Settlements from 1990 to 2019. The period after 2017 is an extrapolation of the trend in the period 2013-2017. This will be updated when the new land use map is available.

Settlements remaining Settlements $\Delta$ to Settlements Settlements total

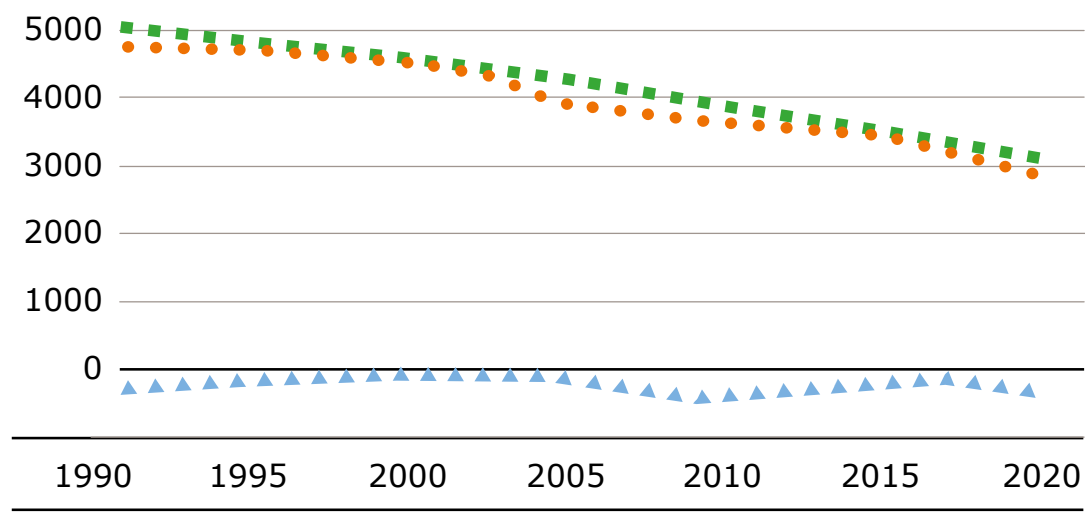

Figure 15: Time series for 1990-2019 of total $\mathrm{CO}_{2}$ emissions/removals in Settlements remaining Settlements and Land converted to Settlements. Data from the NIR 2021.

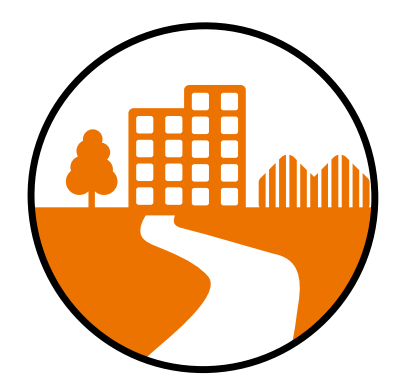

Settlements

Settlements

Settlements remaining Settlements

Land converted to

Settlements

Methods \& Reporting

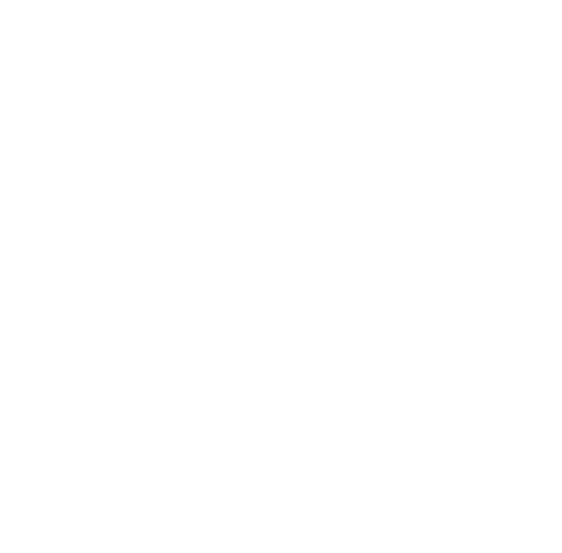




\section{Land converted to Settlements}

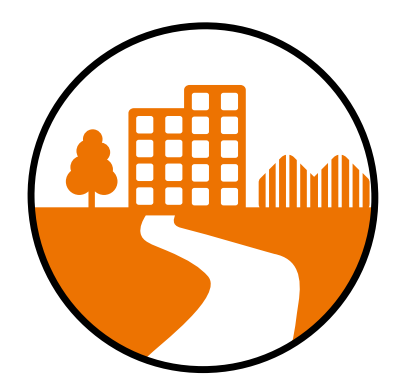

Settlements

current estimate is that $50 \%$ of the Settlements category is paved and has a carbon stock 0.8 times as high as the previous land use. The other $50 \%$ consists of grass or woody elements (trees, bushes) which retain the same carbon stock as before the land-use change. On average, therefore, it is assumed that $90 \%$ of the carbon stock is retained when land is converted to Settlements.

\section{Settlements}

Settlements remaining Settlements

\section{Land converted to Settlements}

\section{Methods \& Reporting}

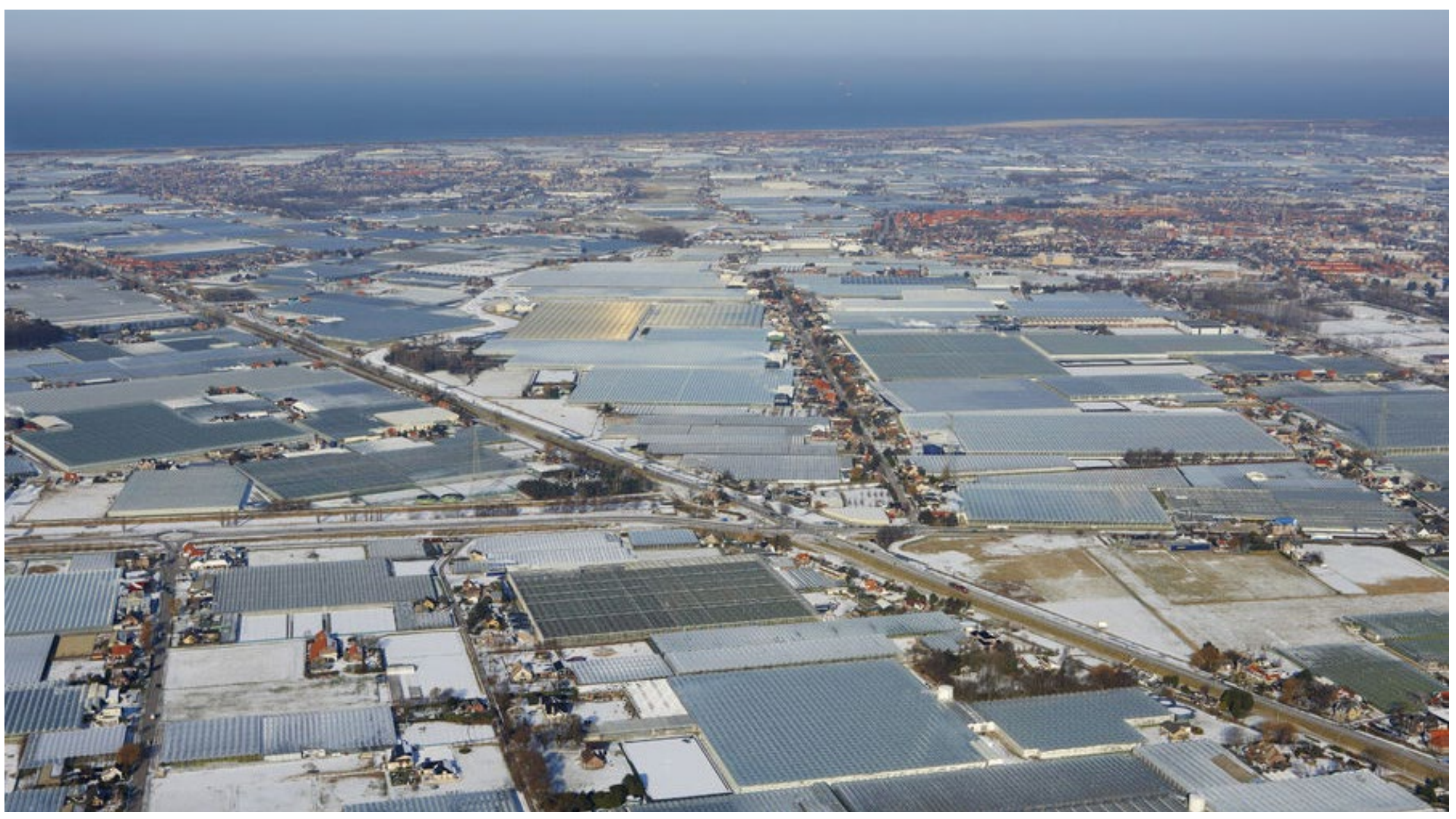

use changes in the Netherlands. It is therefore important to properly estimate the changes in soil carbon stocks. The best

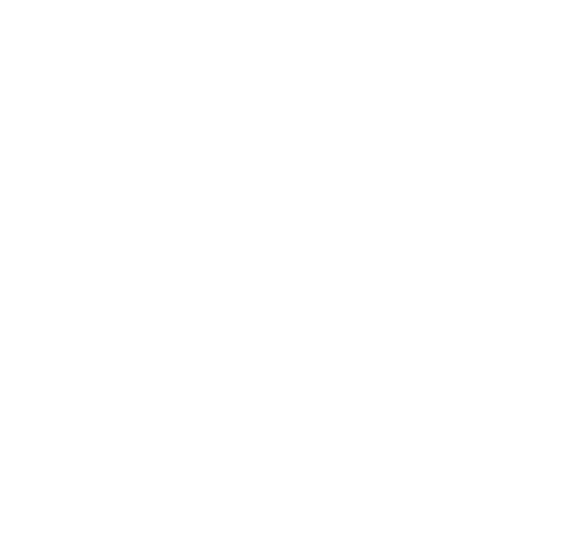




\section{Other Land}

beaches, the coastal dunes and drift sand areas fal within this category. All of these are virtually bare, unvegetated areas.

\section{Definition of land use category 'Other Land'}

Other Land covers land uses that cannot be classified

under any of the other categories. In the Netherlands, only

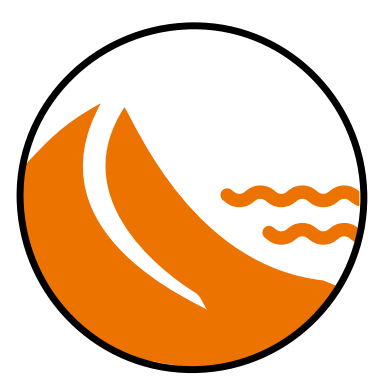

Other Land

\section{Other Land}

Other Land remaining Other Land

Land converted to

Other Land

$M$

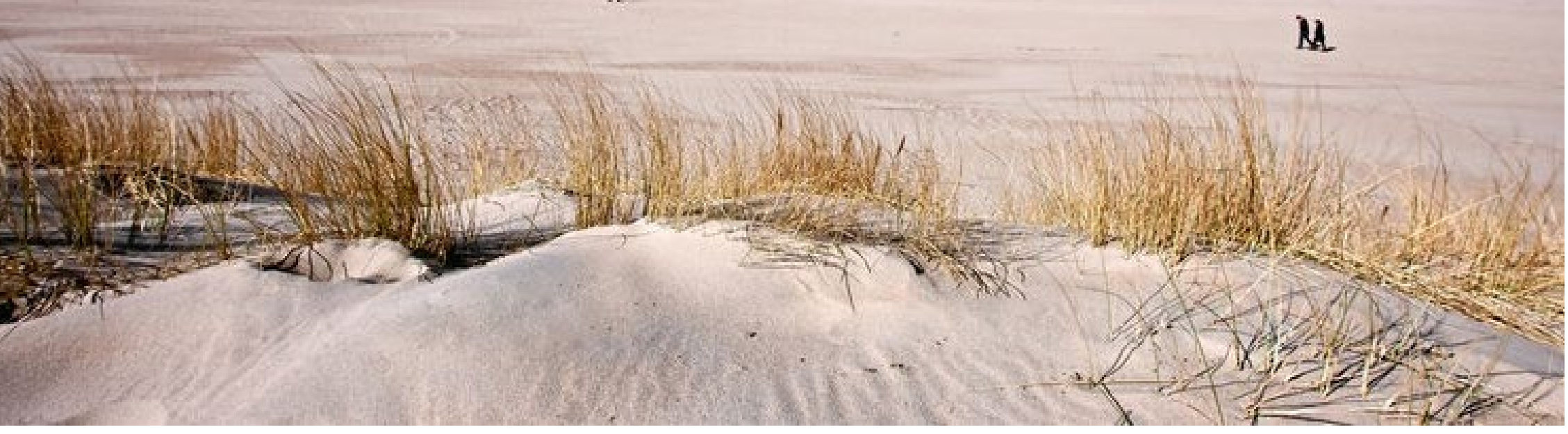

Methods \& Reporting

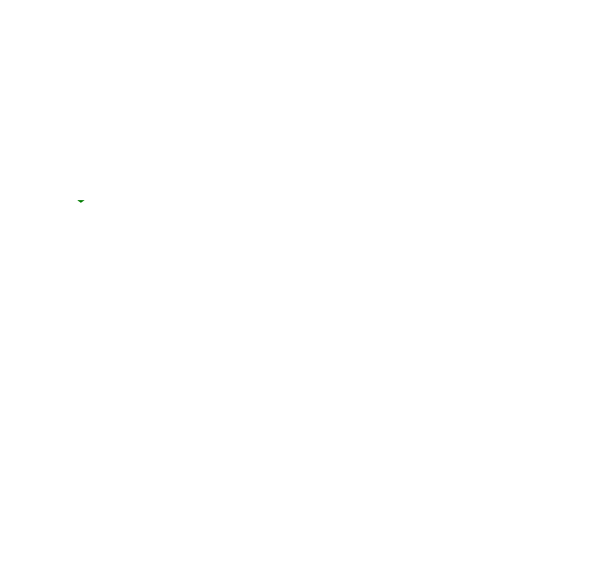




\section{Other Land remaining Other Land}

As the beaches, coastal dunes and drift sand areas which constitute this category are all bare land, there is no living biomass. The area and emissions for Other Land are shown in Figure 16 and 17.

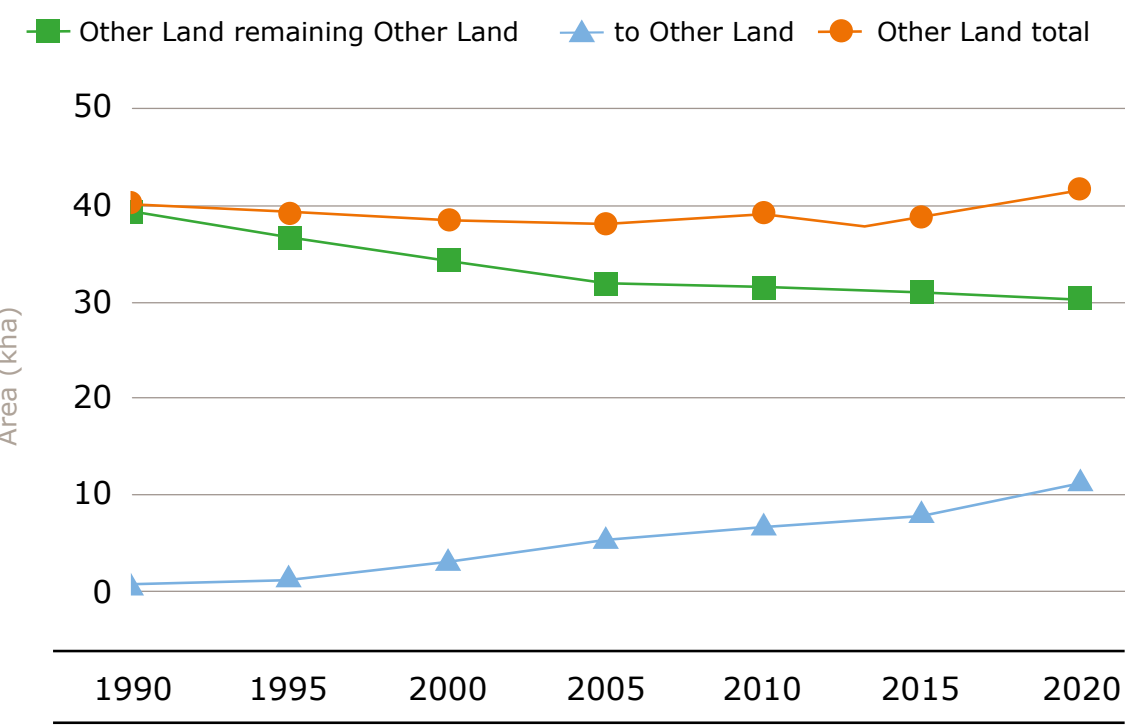

Figure 16: Trends in the area of Other Land from 1990 to 2019. The period after 2017 is an extrapolation of the trend in the period 2013-2017. This will be updated when the new land use map is available.

\section{Other Land remaining Other Land $\quad \Delta$ to Other Land $\quad$ Other Land total}

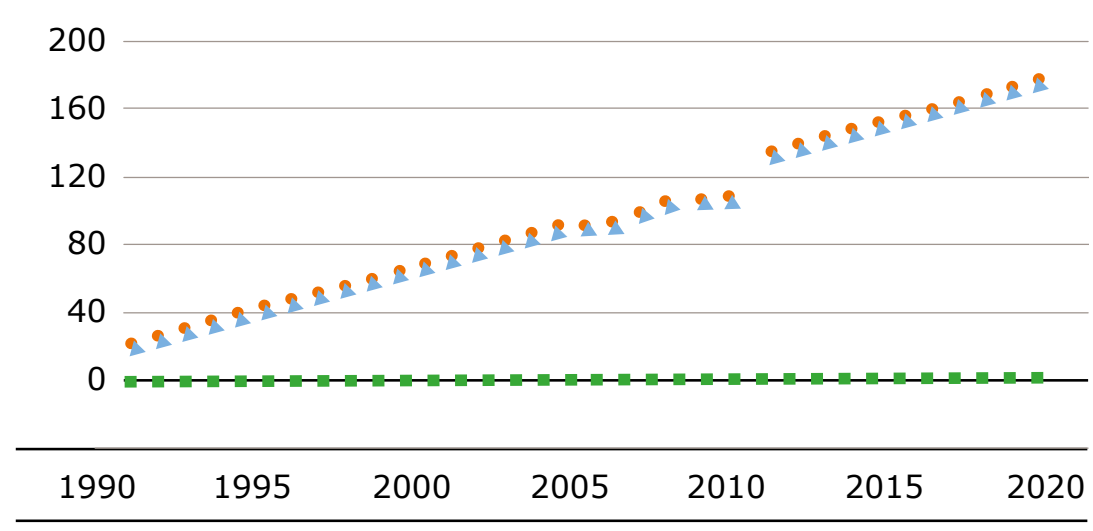

Figure 17: Time series for 1990-2019 of total $\mathrm{CO}_{2}$ emissions/removals in Other Land remaining Other Land and Land converted to Other Land. Data from the NIR 2021.
Other Land

\section{Other Land remaining} Other Land

Land converted to

Other Land

Methods \& Reporting

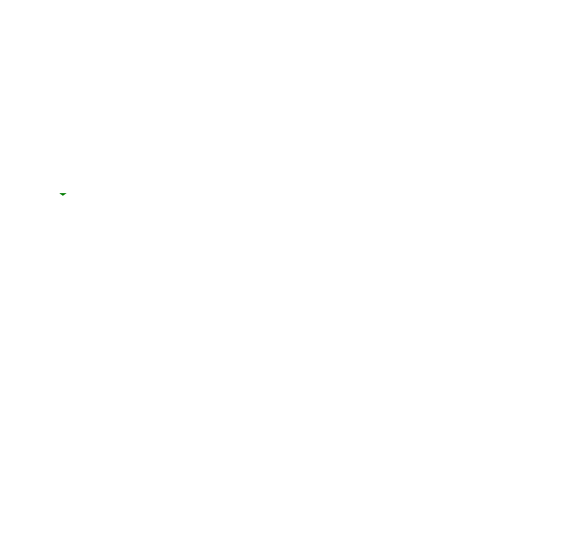




\section{Land converted to Other Land}

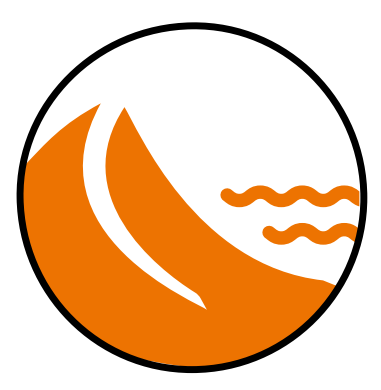

Other Land

Other Land

Other Land remaining Other Land

\section{Land converted to}

Other Land

Methods \& Reporting

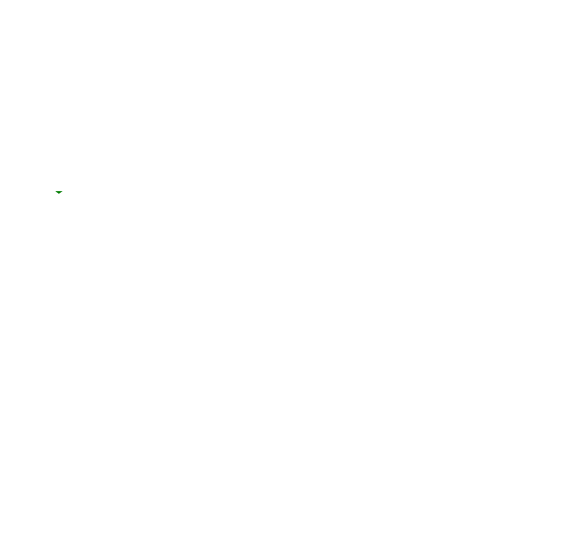




\section{Harvested Wood Products}

The calculations for Harvested Wood Products are based on the IPCC Revised Supplementary Methods and Good Practice Guidance Arising from the Kyoto Protocol.. The carbon stock in Harvested Wood Products is removed from carbon stocks in the Forest Land category from which it is harvested and therefore contributes to the emissions or a reduction in the removals for the Forest Land category. This carbon stock is then included in the Harvested Wood Products category. Deforestation is accounted for as direct emissions (i.e.

instantaneous oxidation).

\section{Definition of the category 'Harvested Wood Products'} The Harvested Wood Products category consists of four different types of products: sawn wood, wood-based panels, other industrial roundwood, and paper and paperboard, each of which has a different lifespan. The stored carbon stocks are released over time, the length of which depends on the lifespan of the products. This is calculated using a first-order decay function with a lifespan-dependent half-life.
The half-life ( 2 years for paper and board, 25 years for wood based panels and 35 years for products made from sawn wood, such as furniture or wood used in construction) indicates the time within which half of the carbon in the products is released again in the form of $\mathrm{CO}_{2}$ emissions. Only wood harvested in the Netherlands needs to be considered under Harvested Wood Products; imported wood is included in the accounts of the producing (exporting) country. An exception to this is wood used for energy generation, as this produces direct emissions after the wood is harvested and is not included in the Harvested Wood Products category. The harvest itself is booked as an emission from Forest Land remaining Forest Land or Land converted to Forest Land. To prevent double counting the use of woody biomass in the energy sector of the NIR is recorded as climate-neutral. Emissions from Harvested Wood Products sent to landfill are not reported separately.

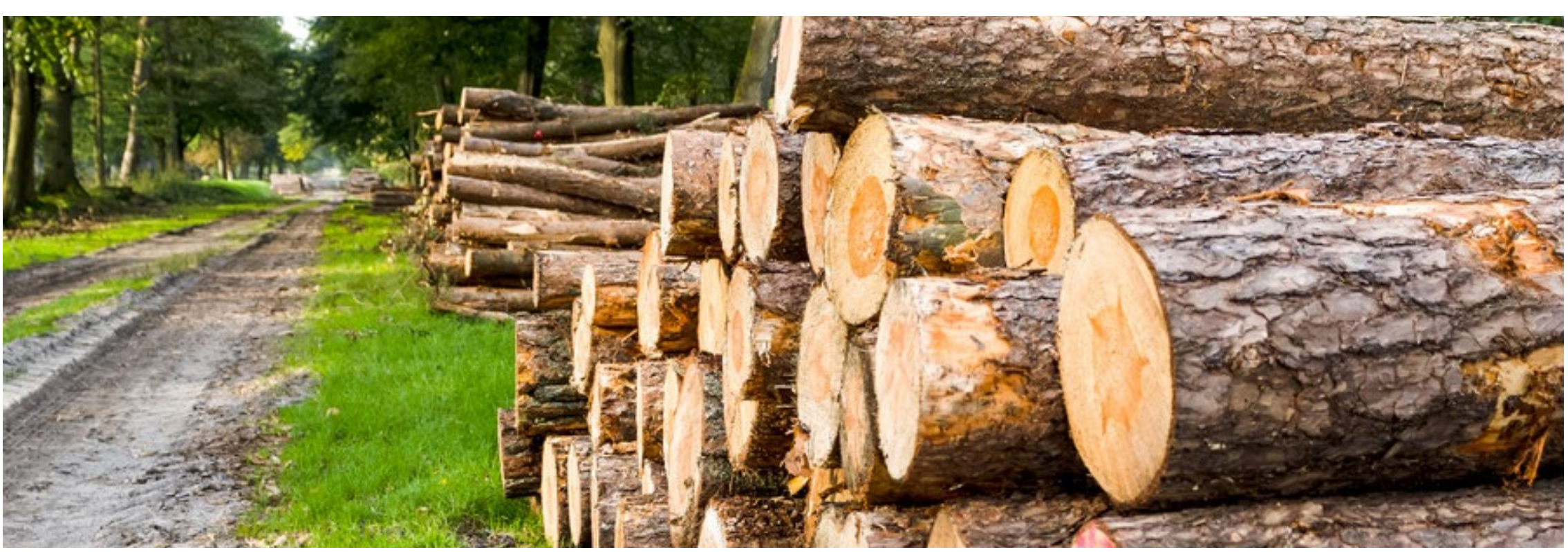

Harvested Wood Products

\section{Harvested Wood Products}

\section{Methods \& Reporting}

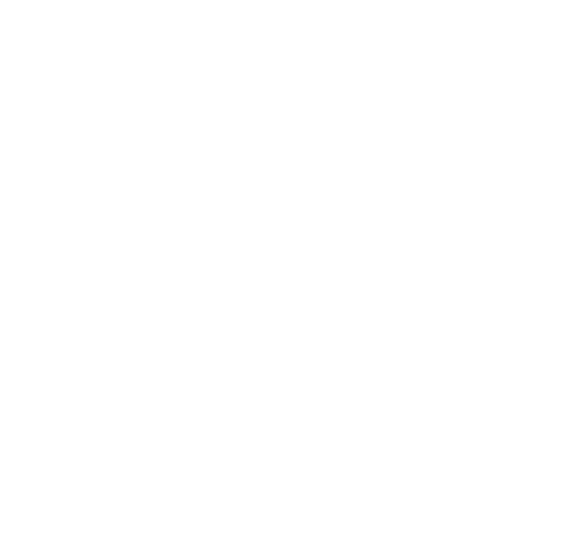




\section{Sources and further reading}

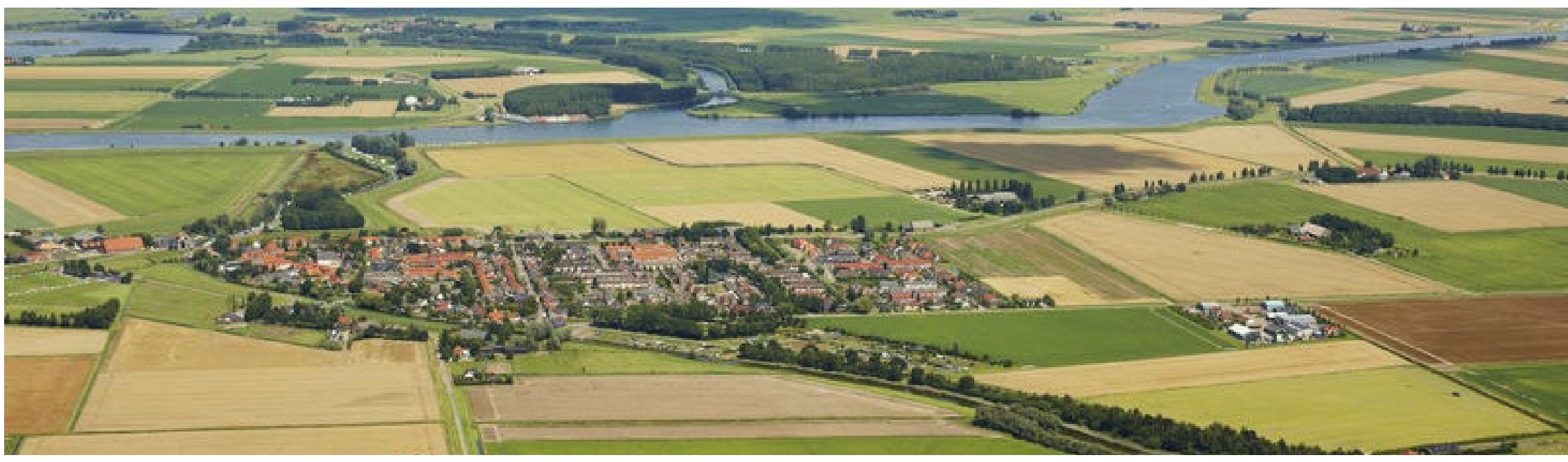

Arets, E.J.M.M., J.W.H. van der Kolk, G.M. Hengeveld, J.P. Lesschen, H. Kramer, P.J. Kuikman and M.J. Schelhaas. (2021). Greenhouse gas reporting of the LULUCF sector in the Netherlands. Methodological background, update 2021. WOt technical report 201. Statutory Research Tasks Unit for Nature \& the Environment (WOT Natuur \& Milieu), Wageningen UR, Wageningen, The Netherlands.

Arets, E.J.M.M., J.P. Lesschen, B.J.W. Lerink, M.J. Schelhaas and C.M.J. Hendriks. (2020). Information on LULUCF actions: The Netherlands Reporting in accordance to Article 10 of Decision No 529/2013/EU. Ministerie van LNV.

Arets, E.J.M.M. and M.J. Schelhaas. (2019). National Forestry Accounting Plan. Submission of the Forest Reference Level 2021-2025 for the Netherlands. Wageningen.

IPCC. (2014). 2013 Revised Supplementary Methods and Good Practice Guidance Arising from the Kyoto Protocol. in T. Hiraishi, Krug, T., Tanabe, K., Srivastava, N., Baasansuren, J., Fukuda, M. and Troxler, T.G., edited by IPCC, Switzerland.

IPCC. (2006). 2006 IPCC Guidelines for National Greenhouse Gas Inventories, Volume 4, Agriculture, Forestry and Other Land Use. IPCC National Greenhouse Gas Inventories Programme. Published by the Institute for Global Environmental Strategies (IGES), Kanagawa, Japan.
Lesschen, J.P., H.I.M. Heesman, J.P. Mol-Dijkstra, A.M. van Doorn, E. Verkaik, I.J.J. van den Wyngaert and P.J. Kuikman. (2012). Mogelijkheden voor koolstofvastlegging in de Nederlandse landbouw en natuur. Alterrarapport 2396. Alterra Wageningen UR, Wageningen, the Netherlands

Ruyssenaars, P.G., P.W.H.G. Coenen, P.J. Zijlema, E.J.M.M. Arets, K. Baas, R. Dröge, G. Geilenkirchen, M. 't Hoen, E. Honig, B. van Huet, E.P. van Huis, W.W.R. Koch, R. te Molder, J.A. Montfoort, T. van der Zee and M.C. van Zanten. (2021). Greenhouse gas emissions in the Netherlands 1990-2019. National Inventory Report 2021 RIVM report 2021-0007. RIVM, National Institute for Public Health and Environment, Bilthoven, the Netherlands.

Schelhaas, M.J., A.P.P.M. Clerkx, W.P. Daamen, J.F. Oldenburger, G. Velema, P. Schnitger, H. Schoonderwoerd and H. Kramer. (2014), Zesde Nederlandse bosinventarisatie: methoden en basisresultaten. Alterra-rapport 2545. Alterra Wageningen UR, Wageningen, the Netherlands.

Schelhaas, M.J., E. Arets and H. Kramer. (2017). Het Nederlandse bos als bron van $\mathrm{CO}_{2}$. Vakblad Natuur Bos Landschap September 2017:6-9.

See also:

www.slimlandgebruik.nl/

www.vbne.nl/klimaatslimbosennatuurbeheer/

\section{Reading Guide}

\section{Introduction}

\section{Emission Register}

\section{Methods \& Reporting}

\section{Accounting Rules}

Greenhouse Gas Emissions

\section{Sources | colofon}

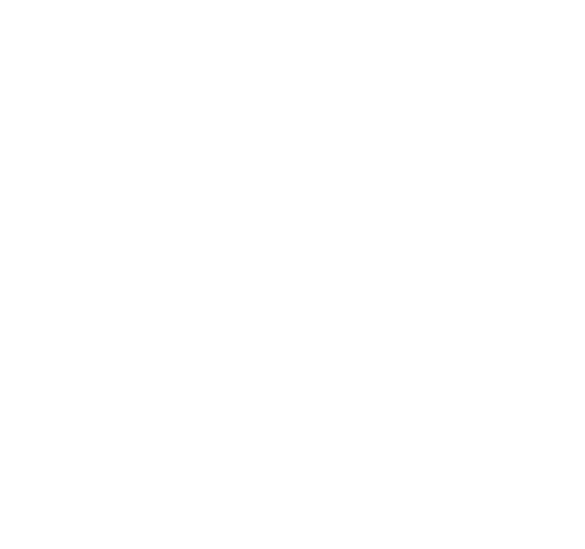




\section{Colofon}

This is a publication by the Statutory Research Tasks Unit for Nature \& the Environment (WOT Natuur \& Milieu), part of Wageningen University $\&$ Research. This publication explains the process of producing the annual reporting of greenhouse gas emissions and removals of $\mathrm{CO}_{2}$ for land use, land-use change and forestry for the Netherlands Pollutant Release and Transfer Register. The methodology described in this publication is reported annually in a WOt technical report. This publication is based on the 2021 version: WOt technical report 201.

If you have any questions or comments about this publication, please contact us.

Publication: WOt special 3, Statutory Research Tasks Unit for Nature \& the Environment (WOT Natuur \& Milieu)

Authors: Chantal Hendriks, Eric Arets and Jolien van Huijstee Editing: Eddy Teenstra

Design: Wageningen University \& Research, Communication Services

Photos: Eddy Teenstra (p6, 24, 26, 30, 32, 35),

Shutterstock (p22, 25, 28, 29, 33, 38, 39, 41, 42, 43),

Paulina Grunwald / Shutterstock.com (p36)

Coordination: Mies van Aar

e-ISSN 2667-1263, DOI: 10.18174/555215, BAPS project number: WOT-04-008-025.01, WOT-04-008-021

(c) 2021 Wettelijke Onderzoekstaken Natuur \& Milieu (Statutory Research Tasks Unit for Nature \& the Environment) PO Box 47, 6700 AA Wageningen

$\mathrm{T}(0317) 485471$

E info.wnm@wur.nl
This publication can be downloaded free of charge from www.doi.org/ $10.18174 / 555215$ and from www.wur.nl/wotnatuurenmilieu

- Acquisition, duplication and transmission of this publication is

permitted with clear acknowledgement of the source.

- Acquisition, duplication and transmission is not permitted for commercial purposes and/or monetary gain.

- Acquisition, duplication and transmission is not permitted of any parts of this publication for which the copyrights clearly rest with other parties and/or are reserved.

The WOt specials series is published by the Statutory Research Tasks Unit for Nature \& the Environment (WOT Natuur \& Milieu), part of

Wageningen University \& Research. WOt specials contain the results of research in a form that is readily accessible to the target group. They pay particular attention to the social debate that is the reason for the research and within which it takes place and to the policy relevance and potential scientific relevance of the results. Research by the Statutory Research Tasks Unit for Nature \& the Environment is financed by the Ministry of Agriculture, Nature and Food Quality (LNV). WOt special 3 was produced in conformity with the Statutory Research Tasks Unit for Nature \& the Environment Quality Management System.

The mission of the Statutory Research Tasks Unit for Nature \& the Environment (WOT Natuur \& Milieu) is to carry out statutory research tasks on issues relating to nature and the environment. These tasks are implemented in order to support the Dutch Minister of Agriculture, Nature and Food Quality, who is responsible for these issues. We provide data about agri-environment, biodiversity and soil information to compile reports as part of national and international obligations, and we work on products of the PBL Netherlands Environmental Assessment Agency, such as the Assessment of the Human Environment reports.
Reading Guide

\section{Introduction}

Emission Register

Methods \& Reporting

Accounting Rules

Greenhouse Gas Emissions

\section{Sources | colofon}

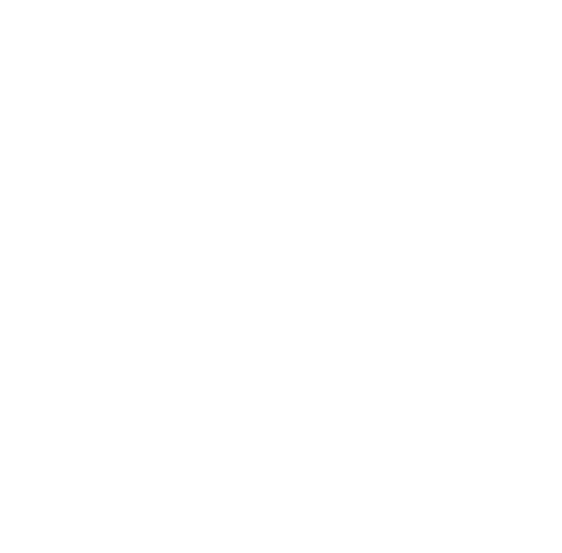

